\title{
Risk Hedging Strategies under Energy System and Climate Policy Uncertainties
}

Volker Krey (krey@iiasa.ac.at), Keywan Riahi (riahi@iiasa.ac.at)

\section{Approved by}

Nebojša Nakićenović

Deputy Director, IIASA

August 2009 


\begin{abstract}
The future development of the energy sector is rife with uncertainties. They concern virtually the entire energy chain, from resource extraction to conversion technologies, energy demand, and the stringency of future environmental policies. Investment decisions today need thus not only to be cost-effective from the present perspective, but have to take into account also the imputed future risks of above uncertainties. This paper introduces a newly developed modeling decision framework with endogenous representation of above uncertainties. We employ stochastic modeling techniques within a system engineering model of the global energy system and implement several alternative representations of risk.

We aim to identify salient characteristics of least-cost risk hedging strategies that are adapted to considerably reduce future risks and are hence robust against a wide range of future uncertainties. These lead to significant changes in response to energy system and carbon price uncertainties, in particular, (i) higher short- to mediumterm investments into advanced technologies, (ii) pronounced emissions reductions, and (iii) diversification of the technology portfolio.

From a methodological perspective, we find that there are strong interactions and synergies between different types of uncertainties. Cost-effective risk hedging strategies thus need to take a holistic view and comprehensively account for all uncertainties jointly. With respect to costs, relatively modest risk premiums (or hedging investments) can significantly reduce the vulnerability of the energy system against the associated uncertainties. The extent of early investments, diversification and emissions reductions, however, depends on the risk premium that decision makers are willing to pay to respond to prevailing uncertainties, and remains thus one of the key policy variables.
\end{abstract}




\section{Contents}

1 Introduction $\quad 1$

2 Stochastic Optimization 3

2.1 Generic Problem Formulations . . . . . . . . . . . . . . . . . . . . 4

2.2 Risk Measures . . . . . . . . . . . . . . . . . . 6

2.3 Numerical Computation . . . . . . . . . . . . . . 8

$\begin{array}{lrr}3 & 3 \text {-Technology Model } & 8\end{array}$

4 Global Energy Systems Model $\quad 11$

4.1 Model Structure and Scenario Assumptions . . . . . . . . . . . . . . . 12

4.2 Stochastic Parameters . . . . . . . . . . . . . . . . . 14

5 Results 16

5.1 Energy System Costs . . . . . . . . . . . . . . . . 16

5.2 Primary Energy Supply . . . . . . . . . . . . . . . . . . 18

$5.3 \mathrm{CO}_{2}$ Emissions . . . . . . . . . . . . . . . 21

5.4 Diversification . . . . . . . . . . . . . . . . . 22

5.5 Energy-related Investments . . . . . . . . . . . . . . . 24

6 Summary and Conclusions $\quad 26$

$\begin{array}{ll}\text { A Model Input Assumptions } & 31\end{array}$

A.1 Demands . . . . . . . . . . . . . . . . . . . 31

A.2 Technologies . . . . . . . . . . . . . . . . 32

A.3 Carbon Price . . . . . . . . . . . . . . . . . 36

B Sample Function Approximation $\quad 37$ 


\title{
Risk Hedging Strategies under Energy System and Climate Policy Uncertainties
}

\author{
VolkerKrey (krey@iiasa.ac.at), KeywanRiahi(riahi@iiasa.ac.at)
}

\section{Introduction}

The future development of the energy system is rife with uncertainties that concern virtually the entire energy chain, from resource extraction to conversion technologies, energy demand, and the stringency of future environmental polices, in particular those addressing climate change. Ignorance with respect to the multitude of uncertainties can be very costly, due to a high share of long-lived capital stock in the energy system and the resulting long time spans that transitions require. Investment decisions today thus need not only to be cost-effective from the present perspective, but have to take into account also the imputed future risks of uncertainties. For energy models and scenario analysis this means that uncertainty needs to be represented endogenously in order to include trade-offs between "optimal" decisions based on most likely developments and risks resulting from uncertainties being resolved in one direction of the other.

Although stochastic optimization techniques have been developed several decades ago [Dantzig, 1955; Beale, 1955], their application to realistic problems has only come into reach in recent years with the evolution of computational resources. Therefore, in the majority of energy studies and models uncertainties are typically treated if at all - by performing sensitivity analysis for a set of parameters. While it is possible through sensitivity analysis to better understand the uncertainty space and broader ranges of future developments, this method is generally not appropriate for identifying robust "hedging" strategies, including response measures and their economic implications to minimize or at least reduce exposure to unwanted risks. More advanced approaches for performing uncertainty analysis include scenario analysis, in particular if performed by multiple models (see [Kann and Weyant, 2000]), as well as robust decision making [Lempert et al., 2006] which aims at deriving robust strategies through iterative multi-scenario simulations.

Different approaches to uncertainty analysis in energy-economic models have been described and systematically categorized by Kann and Weyant [2000], and more recently in Peterson [2006]. With a few exceptions most of the described modeling approaches fall into the category of aggregated top-down models, which lack explicit representation of individual energy technologies. In addition, the majority of the models focuses on uncertainties related to the climate system and climate change related damages with the climate sensitivity being the most popular parameter that is treated as uncertain (e.g. [Manne, 1996; Yohe et al., 2004; Loulou et al., 2009]). 
There are a few technology-explicit bottom-up model applications, e.g. [Messner et al., 1996; Kanudia and Loulou, 1998; Loulou and Kanudia, 1999; Krey et al., 2007; Loulou et al., 2009], however, they concentrate on a very limited number of uncertain parameters in comparison to the total number of parameters included in the models.

In this paper we introduce a newly developed modeling framework of the global energy system that features an endogenous representation of uncertainties. The basic structure of the model builds upon the deterministic energy engineering model MESSAGE [Messner and Strubegger, 1995; Messner et al., 1996; Rao and Riahi, 2006]. We employ risk management techniques, developed for portfolio management applications (cf. [Pflug and Roemisch, 2007]) and incorporate a variety of different representations to measure risks into MESSAGE. Stochastic optimization techniques are then used to solve the resulting stochastic energy systems model. On top of a variety of different risk measures we provide a set of alternative (equivalent) problem formulations (e.g. risk-constrained cost minimization, cost-constrained risk minimization). The different model formulations increase the flexibility of the modeling approach, and permit us to put more or less emphasis on the tails of the uncertainty distribution or to consider different risk-attitudes of decision makers (e.g. towards limiting risks below critical thresholds in contrast to exploring the effect of different levels of risk premiums ${ }^{1}$ ).

In our model application all relevant cost parameters are treated stochastically, i.e. costs concerning the entire chain of energy technologies including resource extraction, energy conversion technologies and energy-saving measures. In addition, to account for the uncertainty of the policy intensity to climate change, the carbon price is also modeled as an uncertain parameter.

Through a series of sensitivity analysis we aim to identify salient characteristics of least-cost hedging strategies that are able to considerably reduce future risks and are hence robust against a wide range of future uncertainties. In particular, we explore the effect of uncertainties on (i) investment decisions in the energy sector, (ii) technology deployment and diversification of the technology portfolio, and (iii) associated greenhouse gas emissions. From a methodological perspective, we are also interested in synergies of hedging strategies against technology- and policy-related uncertainties. Finally, the question of how much risk can be avoided at which cost or, alternatively, whether it is possible to come up with more robust strategies at affordable costs is central to our modeling approach.

The sequel of this paper is structured as follows: In Section 2 we lay out the methodological basis of our modeling framework, starting with various types of problem formulations and risk measures. In the later part of the section we also address the question of how joint distributions of uncertain input parameters are generated. Section 3 illustrates how the methodology operates on the basis of a very simple static 3-technology model. The following Section 4 introduces the central application of this study, the full global energy systems model and the main scenario input assumptions. Appendix A complements this section with more detailed information on the model structure and data. Results of the stochastic modeling exercise are

\footnotetext{
${ }^{1}$ In this article the term risk premium refers to additional expenditures to limit exposure to unwanted risks.
} 
extensively discussed in Section 5, ranging from implications of hedging strategies for primary energy supply and emissions to diversification of the technology portfolio and reallocation of investments within the energy system. The paper concludes with a summary of the main findings in Section 6 .

\section{Stochastic Optimization}

Energy systems models are frequently used to aid scenario analysis and to provide quantitative information about possible future development pathways in the energy sector. In the process of constructing scenarios many assumptions about future developments of socio-economic, demographic and technological change have to be made. In particular, bottom-up energy systems models include a large number of technologies, which need to be represented in a parametric way. How these parameters evolve over time is subject to large uncertainties. In our model we assume all relevant cost parameters (investments, operation and maintenance costs, carbon price) to be uncertain.

The objective of this paper goes beyond the documentation of our stochastic energy systems model, but to provide a modeling framework that is generic enough to be used within (or together with) other similar energy-economic optimization models. To capture different risk attitudes of decision makers, a number of alternative ways of measuring risks (e.g. upper mean absolute deviation, downside risk, Conditional Value-at-Risk) have been implemented. In addition, a variety of alternative (equivalent) problem formulations is provided to increase flexibility of the modeling framework. All formulations have in common that they describe economic trade-offs between decisions based on expected (most likely) future trends and the associated economic risks of the underlying uncertainty. The three alternative problem formulations that we consider are:

1. minimization of a weighted sum of deterministic total system costs and a socalled risk measure as suggested by Messner et al. [1996],

2. minimization of total system costs under constrained risk, and

3. cost-constrained minimization of risk (which considers a maximum risk premium that may be paid for the risk reduction).

As mentioned above, an earlier stochastic version of the MESSAGE model [Messner et al., 1996] used a similar stochastic modeling approach as under point (1), but concentrated on a very limited number of technologies as well as uncertain parameters. Further applications of this type of approach include uncertain import prices of fossil energy carriers [Krey et al., 2007] as well as uncertain increasing returns to scale [Grübler and Gritsevskyi, 2002; Gritsevskyi and Nakićenović, 2000]. A more general discussion of the methodology can be found in [Ermoliev and Wets, 1988; Marti et al., 2004].

We shall next describe the three different problem formulations (Section 2.1), followed by a discussion of the employed risk measures (Section 2.2). 


\subsection{Generic Problem Formulations}

To start with, let us consider the system of equations of a generic inter-temporal deterministic linear programming (LP) minimization problem:

$$
\begin{aligned}
& \min \sum_{t} \mathbf{c}_{t}^{T} \mathbf{x}_{t} \cdot \delta(t) \\
& \mathbf{A x}=\mathbf{b} \\
& \mathbf{x} \geq 0
\end{aligned}
$$

Here $t=1 \ldots T$ is the time-period index, $\mathbf{c}_{t}$ is the cost coefficient vector of the objective function in period $t$ and $\mathbf{x}_{t}$ are the corresponding decision variables in period $t$, with $\mathbf{x}=\left(\mathbf{x}_{1}, \ldots, \mathbf{x}_{T}\right)$ referring to the vector of decision variables for all periods $t=1 \ldots T$. The set of constraints is defined by the matrix $\mathbf{A}$ and the vector of the right hand sides $\mathbf{b}$. The last term in the objective function, $\delta(t)$, is the discount factor. In the following we will refer to the deterministic objective function in the first line of eq. (1) as $F^{\text {det }}(\mathbf{x})$ and to the cost-optimal solution of the deterministic problem as $\mathbf{x}_{\text {det }}^{\star}$.

Based on the above defined deterministic model, we now describe a set of stochastic model versions that include an endogenous representation of risk that result from future uncertainties. For this purpose a risk measure (or risk functional), denoted by $R(\mathbf{x})$, is introduced (see also Section 2.2). Note in particular that the risk measure is an endogenous function of the decision variables $\mathbf{x}$, thus depending on e.g. investment decisions driving technology deployment.

We implemented three alternative problem formulations. From a methodological perspective, the three formulations represent different ways to combine the deterministic objective function, i.e. total system costs $F^{\operatorname{det}}(\mathbf{x})$, and the risk measure $R(\mathbf{x})$. Conceptually, the formulations allow for different policy perspectives, where depending on the context it may be preferable to either control costs, or to control risks, or to define the risk aversion of the decision maker. The formulations are equivalent to each other and can even be combined in a synergistic way as will be discussed later in this section. The three formulations are discussed in turn.

1. Minimization of a weighted sum of deterministic total system costs $F^{\operatorname{det}}(\mathbf{x})$ and the risk measure $R(\mathbf{x})$ :

$$
F^{s t o}(\mathbf{x})=F^{\operatorname{det}}(\mathbf{x})+\rho \cdot R(\mathbf{x}) .
$$

A simple linear combination of deterministic total system costs and risk measure allows to explore the impact of risk on the optimal solution. In this formulation there is no clear focus on either total system costs or risk measure, but the relative weight of the two can be adjusted with the help of the factor $\rho$, an indicator for the risk aversion of the decision maker (cf. [Messner et al., 1996]).

2. Minimization of deterministic total system costs $F^{\operatorname{det}}(\mathbf{x})$ under constrained risk measure $R(\mathbf{x})$ :

$$
\begin{aligned}
& \min F^{\operatorname{det}}(\mathbf{x}) \\
& \text { s.t. } R(\mathbf{x}) \leq R^{\max }
\end{aligned}
$$


In this formulation the emphasis is on risk reduction. From the perspective of a decision maker the focus is to reduce the risk by constraining the risk measure $R(\mathbf{x})$ to a maximal permissible value. The cost minimization then guarantees that a solution is on the efficient frontier, i.e. the risk level $R^{\max }$ is achieved at lowest possible costs. The formulation is particularly important if critical thresholds for risks can be identified. A practical example would be local water supply management, which typically focuses on the optimal allocation of resources in order to reduce the risk of supply-shortages below certain levels [Dessai and Hulme, 2007].

3. Minimization of risk measure $R(\mathbf{x})$ under constrained expected total system $\operatorname{costs} F^{\operatorname{det}}(\mathbf{x})$ :

$$
\begin{aligned}
& \min R(\mathbf{x}) \\
& \text { s.t. } F^{\operatorname{det}}(\mathbf{x}) \leq(1+f) \cdot F^{\operatorname{det}}\left(\mathbf{x}_{\text {det }}^{\star}\right)
\end{aligned}
$$

In contrast to the previously presented formulation here the focus is to control the risk premium, i.e. the "additional" costs for reducing risk. These "hedging expenditures" are limited to a fraction $f$ of the total costs in absence of uncertainty (the costs of the deterministic solution $F^{\operatorname{det} \star}=F^{\operatorname{det}}\left(\mathbf{x}_{\text {det }}^{\star}\right)$ ). The objective of this problem formulation is then to minimize the resulting risk (given budgetary constraints for the risk premium). This formulation gains importance if risk thresholds can not be identified, or when the problem is characterized by large complexity. Particularly in the latter case a sensitivity analysis for different risk premiums can provide important policy insights, enhancing the understanding of the magnitude of risk that can be reduced at specific costs. Future energy projections, as explored in our paper, are a typical example of a complex problem with often counter-acting uncertainties (e.g. the increasing likelihood of high carbon prices and the uncertainty of future cost improvements for new zero-emissions technologies are pulling the solution into opposite directions). We will come back to this and primarily use this formulation for illustrating our results. ${ }^{2}$

The three formulations are - with appropriately chosen parameters $R^{\max }, f$ and $\rho$ - equivalent to each other and their combined use can help to understand different aspects of risk hedging strategies. Cost constrained risk minimization (3) has the advantage of being comparatively easy to interpret and to communicate, since the hedging cost $f$ denotes in essence a risk or insurance premium known also to non-experts in stochastic methods. However, a drawback is that the risk measure defines the objective function, leading to shadow prices of e.g. energy carriers or carbon emissions which are not comparable with those of the deterministic model. Therefore, combining cost-constrained risk minimization and risk-constrained cost

\footnotetext{
${ }^{2}$ From a technical perspective, the latter two formulations have the advantage that the relative orders of magnitude of total system costs $F^{\text {det }}(\mathbf{x})$ and risk measure $R(\mathbf{x})$ can be allowed to be very different. This happens, e.g. in the case of a linear cost function and a quadratic risk measure (e.g. semi-variance, see Section 2.2). Apparently this situation causes problems in the third case, because one of the two terms then dominates the other one for $\rho \sim 1$, thus the magnitude of $\rho$ has to be chosen individually for each risk measure used.
} 
minimization allows a complementary view on the problem by determining the risk level corresponding to a certain risk premium $f$ first and then running the model again in the risk constrained formulation that allows obtaining "ordinary" shadow prices, like marginal carbon abatement costs. Another interesting aspect is that the linear combination $F^{\text {sto }}(\mathbf{x})$ of expected costs and risk measure implies that by definition - the gradients of deterministic total system $\operatorname{costs} \operatorname{grad} F^{\operatorname{det}}(\mathbf{x})$ and marginal (weighted) risk measure $\rho \cdot \operatorname{grad} R(\mathbf{x})$ are equal with opposite sign at the solution $\mathbf{x}_{\text {sto }}^{\star}$. Therefore, the trade-off between expected costs and risk is explicitly included in the objective function. With an appropriately chosen $\rho$ this allows deriving an "optimal" level of risk - an admittedly hypothetical concept, but with clear methodological advantages for exploring cost-benefit analysis of e.g. climate change.

\section{$2.2 \quad$ Risk Measures}

As stated above, we are interested in a generic framework for risk assessment rather than a particular type of formulation. Therefore, in addition to the different problem formulations presented above, we have implemented a number of - partly well-known - risk measures. Similar to the alternative problem formulations the choice of an appropriate risk measure depends on the risk attitude of a decision maker as well as on the specific characteristics of the problem under consideration. For instance, if low probability high impact events are of particular interest, a risk measure that focuses on the tail of the distribution (e.g. semi-variance, $\beta$-CVaR) is more appropriate than one that equally weights all positive deviations from the expected value (e.g. upper mean absolute deviation).

In the following, $\mathbf{c}_{t}(\omega)$ and $\overline{\mathbf{c}}_{t}$ are the stochastic cost parameters in period $t$ and their expected values, respectively. For practical reasons, i.e. to ensure solvability of the problem we restrict ourselves to measures that are implementable in linear and quadratic programming.

1. The upper mean absolute deviation is a linear risk measure originally used by Messner et al. [1996] and is defined in the following way:

$$
R(\mathbf{x}, \omega)=\sum_{t} \max \left\{0,\left[\mathbf{c}_{t}(\omega)-\overline{\mathbf{c}}_{t}\right]^{T} \mathbf{x}\right\} \cdot \delta(t)
$$

It's expected value $R(\mathbf{x})=\mathbf{E}_{\omega} R(\mathbf{x}, \omega)$ corresponds the expected underestimation of total system costs which is used to measure the economic risk associated with a strategy $\mathbf{x}$.

2. Conditional Value-at-Risk ( $C V a R$ ), also referred to as expected shortfall, is related to the above defined upper mean absolute deviation, but only takes the worst $(1-\beta)$ fraction of outcomes into consideration, where $\beta$ typically is chosen to be $0.90,0.95$ or 0.99 . Our model implementation is based on the work of Rockafellar and Uryasev [2000] which, in addition to the risk measure's 
definition in eq. (2) requires the following two equations:

$$
\begin{aligned}
& \operatorname{CVaR}(\mathbf{x})=\mathbf{E}_{\omega} \sum_{t}\left\{\alpha_{t}(1-\beta)^{-1} \cdot z_{t}(\omega) \cdot \delta_{t}\right\} \\
& R(\mathbf{x}, \omega, t)=\alpha_{t}-z_{t}(\omega)
\end{aligned}
$$

Here $\alpha_{t}$ serves as a proxy for the so-called Value-at-Risk in period $t$ and $z_{t}(\omega)$ is an auxiliary variable. More background information and details on the implementation can be found in [Palmquist et al., 1999; Rockafellar and Uryasev, 2000].

3. Semi-variance or downside risk:

$$
R(\mathbf{x}, \omega)=\sum_{t}\left(\max \left\{0,\left[\mathbf{c}_{t}(\omega)-\overline{\mathbf{c}}_{t}\right]^{T} \mathbf{x}\right\}\right)^{2} \cdot \delta(t)
$$

The expected value of this quadratic risk measure corresponds to a semivariance, i.e. only positive deviations contribute to it, but in contrast to eq. (2) quadratically.

4. Linear-Quadratic Risk-Benefit Function

$$
R(\mathbf{x}, \omega)=\sum_{t}\left\{\gamma \cdot\left(\max \left\{0,\left[\mathbf{c}_{t}(\omega)-\overline{\mathbf{c}}_{t}\right]^{T}\right\} \mathbf{x}\right)^{2}-\min \left\{0,\left[\mathbf{c}_{t}(\omega)-\overline{\mathbf{c}}_{t}\right]^{T}\right\} \mathbf{x}\right\} \cdot \delta(t)
$$

Following the arguments by Grübler and Gritsevskyi [2002], positive deviations from the expected costs $\overline{\mathbf{c}}_{t}$ contribute quadratically to the risk-benefit function whereas negative contributions, i.e. opportunities or benefits contribute linearly. This formulation reflects that underestimating costs is penalized more heavily in competitive markets than overestimation. From a company's perspective the latter might result in lower profits whereas the former can result in bankruptcy.

The first three risk measures are well-known and widely used in the finance and risk management literature (cf. [Pflug and Roemisch, 2007]), even though they have rarely been applied to energy-economic problems. To a large extent the alternative risk measures represent different risk attitudes towards either the average risk or extreme tail events. For example, the quadratic risk measures (eq. 3 and 4) put much more emphasis on the "low probability high cost" events in the tails of the distributions compared to the upper mean absolute deviation in eq. (2), which averages risks over the whole range of excess costs. Similarly, the case of CVaR represents also risk aversion towards the tails, since per definition only the worst (1$\beta$ ) fraction of realizations is taken into account. A specific characteristic of the linearquadratic risk measure in eq. (4) is that is takes opportunities into consideration. However, if distributions are sufficiently wide, the quadratic part typically dominates the linear one such that results turn out to be very close to that of the semi-variance (eq. 3). 


\subsection{Numerical Computation}

We assume distribution functions for the stochastic cost parameters (see Section 4.2). For practical implementation purposes we draw a finite number of $N$ samples from these joint distributions. By doing so we obtain a numerical estimate of the risk measure $R(\mathbf{x})$ as defined in eq. (5) below

$$
R(\mathbf{x}) \rightarrow R^{N}(\mathbf{x})=\frac{1}{N} \sum_{s=1}^{N} R\left(\mathbf{x}, \omega^{s}\right) .
$$

Given the sampling procedure the approach can be referred to as distribution-free. The quality of the solution critically depends on the sample size. In other words, $N$ needs to be selected large enough, so that it approximates a solution with $N \rightarrow \infty$. We assess the minimum sample size through experiments, where $N$ is increased until solutions converge and outcomes do not show any qualitative difference. A detailed description of the convergence criterion as well as the sampling techniques can be found in Appendix B.

We also account for correlations between uncertain parameters (see Section 4.2). Depending on the sampling algorithm, we use either so-called copulae (in case of random sampling) or the algorithm suggested by Iman and Conover [1982] (in case of latin hypercube sampling) to induce correlation among uncertain parameters. ${ }^{3}$

\section{3-Technology Model}

This section presents results from a very simple and idealized model with the aim to illustrate from a conceptual point of view, how in our modeling approach uncertainties and risks affect the decision making process.

The simple model consists of just three variables $x, y$, and $z$. In the energy context these three variables can be thought of as different types of power plants (e.g. natural gas, coal, nuclear) with expected values for electricity generation costs $\bar{c}_{x}, \bar{c}_{y}$ and $\bar{c}_{z}$ respectively. Uncertainties with respect to costs, characterized by the variance $\sigma_{i}^{2}$, are assumed to differ across the three technologies (see Table 1 ). The three power plants need to supply an electricity demand $d$. To further complication from inter-temporal effects, the model is chosen to be static.

Assuming that there is no uncertainty, the problem formulation is reduced to the simple deterministic objective function $F^{\text {det }}(x, y, z)=\bar{c}_{x} x+\bar{c}_{y} y+\bar{c}_{z} z$. Due to the employed cost-minimization the model suggests to deploy only the cheapest technology. Even if cost-differences between technologies would be very minimal, the winner always takes it all. In our example this is the natural gas power plant in the upper left corner of Figure 1(a) which illustrates the total system costs of the deterministic objective function. The lines in Figure 1(a) denote cost meridians of identical system costs for a combination of nuclear and natural gas shares in total

\footnotetext{
${ }^{3}$ For $k$ parameters, as a result of both procedures we obtain samples on the $k$-dimensional unit cube $[0,1]^{k}$ that can subsequently be transformed into arbitrary distributions with the corresponding quantile functions. Samples are generated with the help of the graphics and statistics software R [R Development Core Team, 2008], making use of several add-on packages [Carnell, 2006; Yan, 2007].
} 
demand. Naturally the lower the contribution of natural gas becomes, the more the other technologies need to be deployed, leading consequently also to an increase in the system costs. The third variable $z$ (coal) is not shown explicitly, because its contribution corresponds just to the gap between the other two technologies' supplies and the demand, that is $z=d-x-y \cdot{ }^{4}$ A major drawback of the deterministic solution is that it always features the least cost option supplying the total demand. Small changes in cost assumptions may thus dominate the results, with switching between one extreme to another. This behavior is known as penny switching or knife edge effect of linear programming.

\begin{tabular}{llrr}
\hline Variable & Technology & $\bar{c}_{i}[\mathrm{ct} / \mathrm{kWh}]$ & $\sigma_{i}[\mathrm{ct} / \mathrm{kWh}]$ \\
\hline$x$ & Nuclear Power Plant & 4.5 & 1.0 \\
$y$ & Natural Gas Power Plant & 3.5 & 1.5 \\
$z$ & Coal Power Plant & 4.0 & 1.25 \\
\hline
\end{tabular}

Table 1: Technology specifications in the 3-technology model.

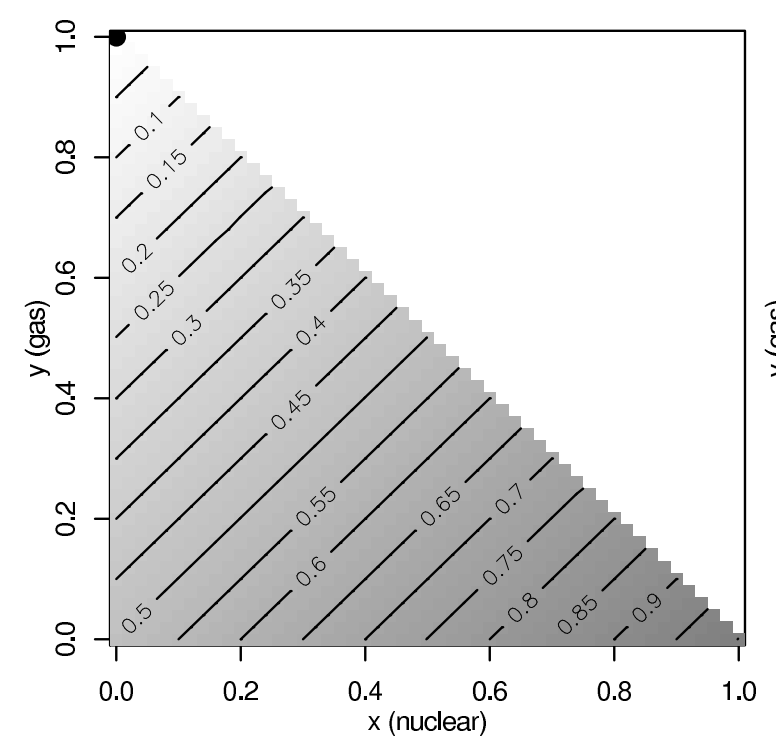

(a) total system costs

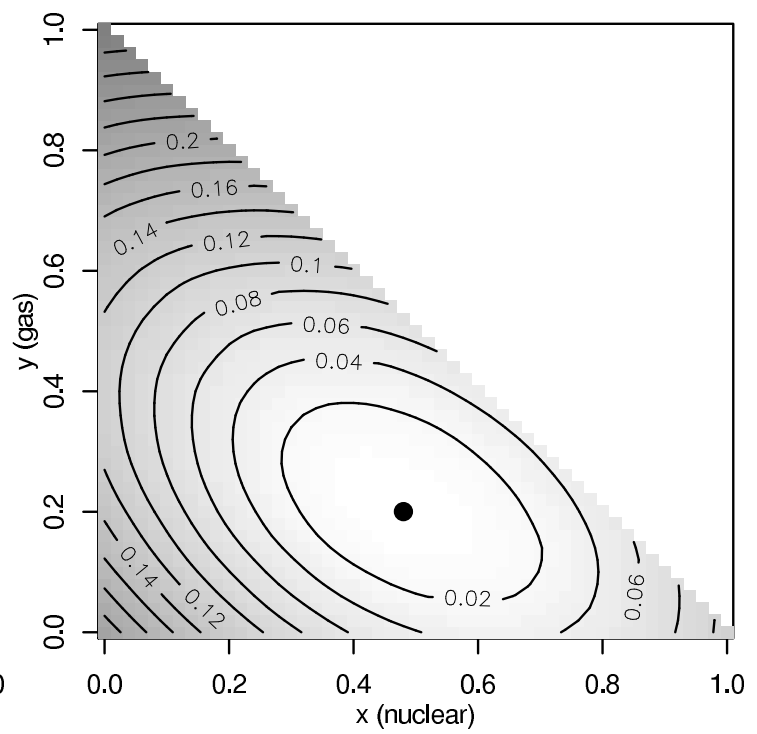

(b) risk measure

Figure 1: Illustration of (a) total system cost $F^{\operatorname{det}}(x, y, z)$ and (b) risk measure $R(x, y, z)$ as a function of technology activities

Panel (b) in Figure 1 shows the values of the risk measure $R(x, y, z)$ if we assume that the costs are uncertain. ${ }^{5}$ As illustrated by the graph, also $R(x, y, z)$ is dependent on the share of the individual technologies. From a pure risk perspective, however, natural gas has for example become much less attractive due to its high cost uncertainty (see standard deviations $\sigma_{i}$ in Table 1). Most importantly, the risk measure in Figure 1(b) features a minimum - again indicated by the black dot - that corresponds to a diversified technology portfolio with contributions of all the three power plant types. In that sense, the model confirms the well-known

\footnotetext{
${ }^{4}$ In the numerical example without loss of generality the demand is set to $d=1$.

${ }^{5}$ We implemented the risk measure as defined by the upper mean absolute deviation as defined in eq. (2).
} 
rule that in the case of uncertainty it is advisable "not to put all the eggs into one basket". To which extent diversification or hedging can help to reduce the imputed risk of uncertainty depends on the problem at hand and the model formulations presented further above (Section 2.1). Regardless of the problem formulation, robust response strategies need to consider both panels of Figure 1, and the economic trade-off between the expected costs $F^{\text {det }}$ as well as the imputed risk $R$.

It needs to be emphasized that diversification can only help as a hedging strategy, if the costs of the technologies are not perfectly correlated. In case of highly correlated electricity generation costs it is for example preferable to mostly choose the technology with less volatile costs to minimize the risk measure. This behavior is illustrated in Figure 2 where the correlation coefficient $\rho_{y z}$ between gas- and coal-fired electricity generation is varied between 0 and 1 . With increasing correlation the share of natural gas at minimal risk is reduced to zero in comparison to more than $20 \%$ in the case without correlation. Note also that the share of the uncorrelated nuclear plant is increasing in response to the cost-dependency between coal and gas. This has important practical implications for the bigger global energy systems model, presented in the next section.
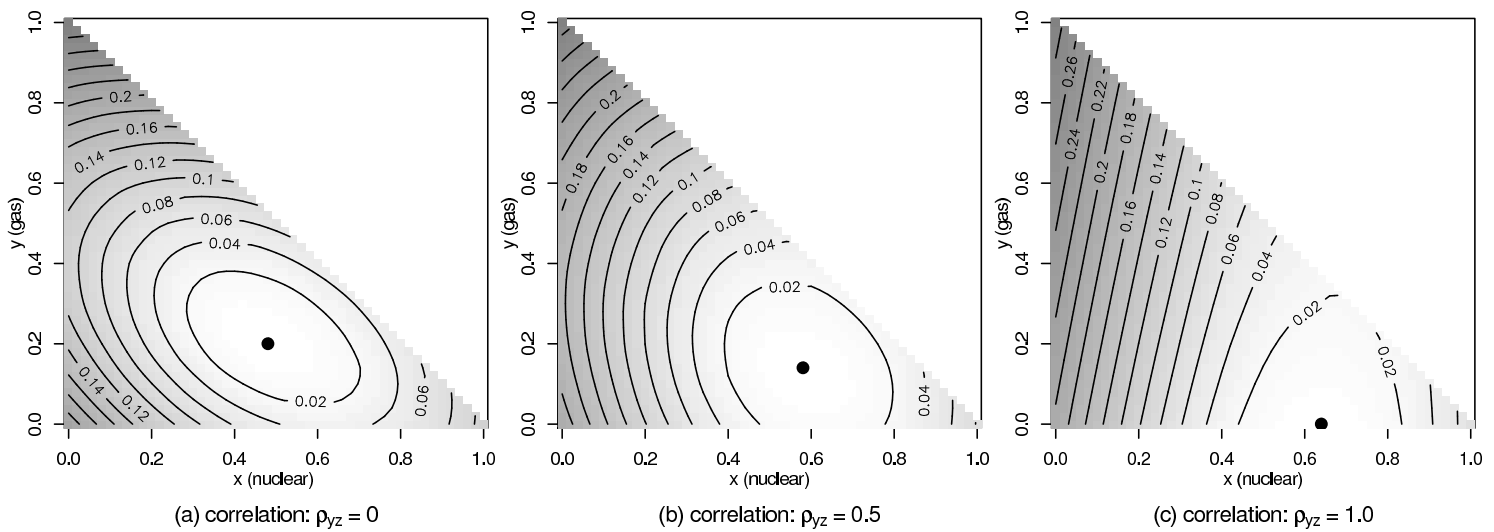

Figure 2: Influence of correlation on diversification of the technology portfolio for correlations (a) $\rho_{y z}=0$ (b) $\rho_{y z}=0.5$ and (c) $\rho_{y z}=1$

The introduction of an uncertain carbon price would influence the cost distributions of the three technologies in our example very differently. The cost distribution of nuclear as a carbon-free technology would not change at all whereas gas- and in particular coal-fired power generation would be penalized by shifting the distributions towards higher costs. As a result the optimal share of nuclear in a risk-minimal portfolio would increase whereas coal's contribution would decrease.

The combination of expected costs $F^{\text {det }}$ and risk measure $R$ in our modeling framework is different for the three formulations described in Section 2.1. The mechanism of the three formulations is illustrated graphically in Figure 3. As in the previous figures the corresponding minima are again indicated by the black dots in the graphs.

The left hand panel of Figure 3 represents risk-constrained cost minimization, i.e. the objective function is identical to that of the deterministic model. In addition, the risk constraint $R^{\max }$ - indicated by the red dashed line - is projected onto the surface of the cost function. The resulting cost-minimum corresponds to 


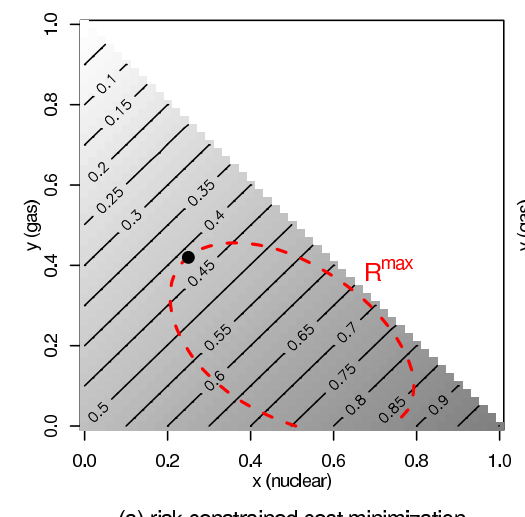

(a) risk constrained cost minimization

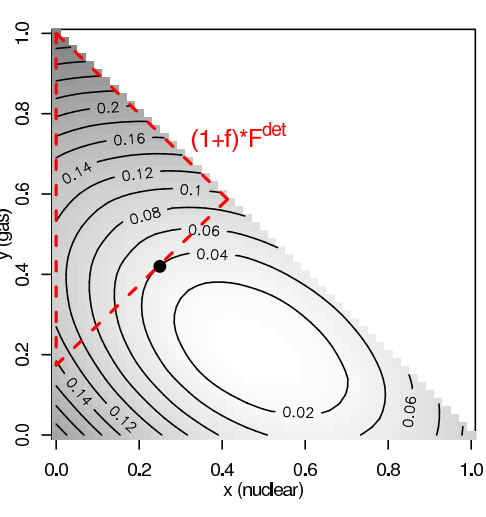

(b) cost constrained risk minimization

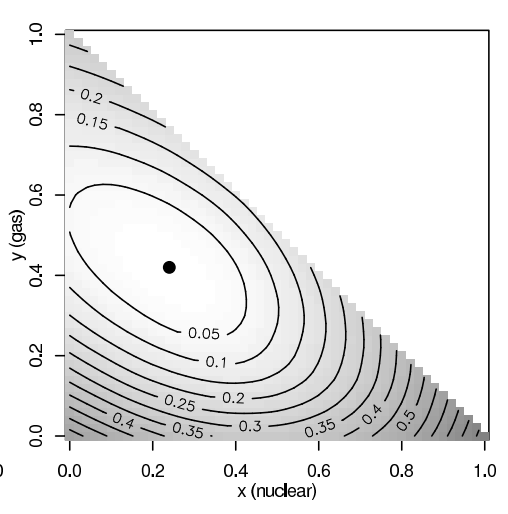

(c) linear combination

Figure 3: Illustration of alternative model formulations: (a) minimization of a linear combination of total system costs and risk measure (b) minimization of total system costs under a risk constraint (c) minimization of the risk measure under a cost constraint

a technology portfolio on the edge of the $R^{\max }$ surface with the lowest possible objective function value. The risk constraint $R^{\max }$ excludes the optimal deterministic solution featuring the extreme of $100 \%$ gas electricity generation. Consequently, all three power plants contribute to electricity generation.

Figure 3(b) denotes the result of a cost-constraint risk minimization. Panel (b) thus shows the risk measure $R$ with the cost constraint $(1+f) \cdot F^{\text {det }}$ projected onto its surface as the red dashed line. The resulting risk minimum corresponds to a technology portfolio on the edge of the surface denoted by the cost constraint. Synonymous to the above implementation, the cost constraint $(1+f) \cdot F^{\text {det }}$ excludes the minimum risk solution, thus e.g. natural gas shares are higher than in a case with pure risk minimization.

The third graph on the right side of Figure 3 corresponds to a linear combination of expected costs $F^{\text {det* }}$ and risk measure $R$, also featuring an optimum with a diversified technology portfolio. Moreover, the three Figures 3 (a) - (c) illustrate the equivalence between the three alternative problem formulations. As a result the optimum is identical in the three formulations if the parameters $\rho, R^{\max }$ and $f$ are chosen accordingly. Although mathematically equivalent, from a conceptual perspective the three formulations allow for different policy perspectives, where depending on the context it may be preferable to either control risk (left panel) or costs (middle panel), or to define specific risk aversion of the decision maker (right panel).

We move next to the more complex global energy systems model, and the implementation of uncertainty into a "real world problem".

\section{Global Energy Systems Model}

In order to explore the impact of cost uncertainties on optimal transitions within the global energy system and the resulting development pathways, we employ above methodologies within a systems engineering model. On the one hand a relatively 
simple or stylized model structure is a precondition to keep the model transparent and the results interpretable. On the other hand, stochastic modeling approaches are computationally more demanding than deterministic models and therefore put limitations on the number of stochastically treated parameters. Compared to other energy-economic models, our framework is thus of intermediate complexity, characterized by a relatively comprehensive representation of energy technologies within a single world-region.

\subsection{Model Structure and Scenario Assumptions}

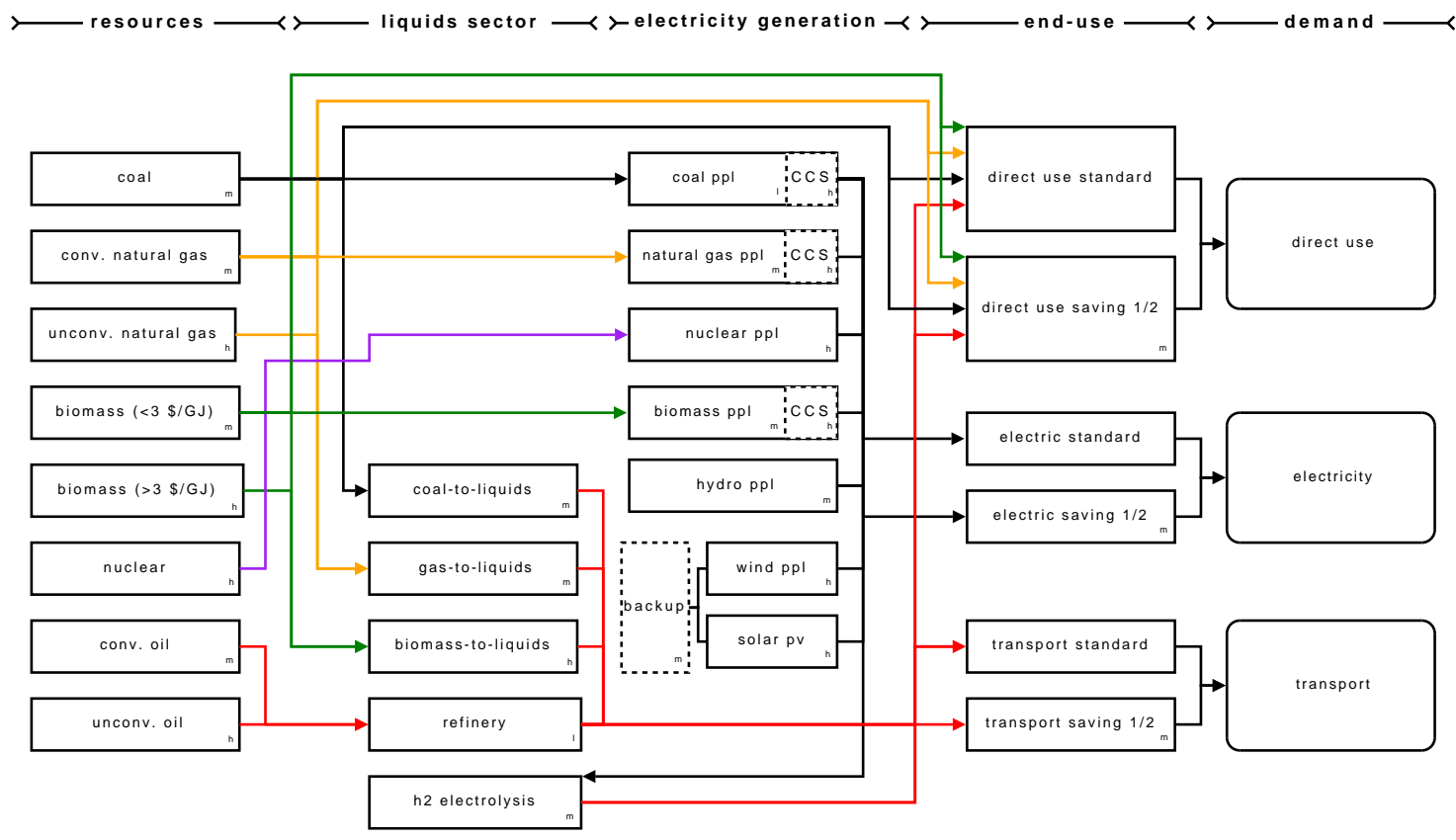

Figure 4: Reference energy system of the one-regional global model

Figure 4 provides a schematic illustration of the model's reference energy system (RES). The RES is designed to cover a large number of possible energy supply chains, from primary energy extraction, to a range of energy conversion technologies, and the transmission and distribution of final energy carries to three aggregated demand sectors.

The model includes various fossil, nuclear and renewable energy resources along with estimates of the associated potentials and extraction costs (see left-hand side of Figure 4). The conversion sector consists of nine electricity generation technologies with the possibility of carbon capture and storage from fossil- and biomass-based power generation. In addition the model considers five alternative technologies to supply liquid fuels, including refineries for oil-products as well as coal, gas, and biomass to liquid options and hydrogen ${ }^{6}$. Transportation and distribution costs

\footnotetext{
${ }^{6}$ Hydrogen production is limited to electrolysis. While this permits that hydrogen is produced from all primary fuels, we did not consider other technologies such as natural gas steam reforming in order to keep the number of technologies as small as possible for the computationally expensive stochastic optimization.
} 
of particularly grid-bound energy carriers, such as electricity and natural gas are considered as well, however, they are not shown explicitly in Figure 4.

The demand side is more aggregated than the supply side and distinguishes three demand categories for electric, non-electric (direct use) and transportation fuel demand. In the demand sectors we currently do not model individual appliances, but use energy conservation cost curves. The reference demand is based on the B2 scenario [Riahi and Roehrl, 2000] from the IPCC Special Report on Emissions Scenarios (SRES) [Nakićenović and Swart, 2000]. The parameterization of the conservation cost curves and the corresponding energy conservation potentials are derived from the recent update of the B2 scenario using the IIASA Integrated Assessment modeling framework [Riahi et al., 2007; IIASA GGI, 2007] including the detailed 11-regional MESSAGE-MACRO model [Messner and Schrattenholzer, 2000; Riahi et al., 2007] $]^{7}$.

Large-scale energy systems models typically include a number of additional restrictions or constraints in order to (i) avoid typical penny switching effects of linear programming approaches and (ii) guide the model into a "realistic" direction. Such external model guidance often mimics market penetration limitations of specific technologies, remain however to some extent arbitrary with limited empirical basis. In contrast to this practice, we do only include restrictions that have a physical or technical motivation, like e.g. resource availability, renewable potentials, maximum share of intermittent electricity generation ( $25 \%$ of final demand, otherwise additional backup capacity needed) or baseload constraints (60\% of final electricity demand). An exception is the use of solid fuels in the end-use sectors which is limited to the level of the B2 baseline [IIASA GGI, 2007] in order to mimic non-economic considerations and inconvenience of solid fuel consumption at the consumer level.

The main underlying assumptions with respect to scenario drivers, such as economic growth, population, or technological change build upon the B2 SRES storyline, and the most recent quantitative update summarized in Riahi et al. [2007]. The B2 scenario is a middle of the road "dynamics as usual" scenario, which combines intermediate population and economic growth with modest, but balanced technology improvements. The balanced and intermediate characteristic of the scenario makes it ideal for defining the expected values in our analysis. Hence, the parameterization of the technologies, including the evolution of expected costs over time, and energy demand stem mainly from the B2 scenario. In addition, we build upon the review of technological change in the scenario literature performed by Nakicenovic and Riahi [2001], which analyzes future distributions of costs of three ensembles of scenarios for the World Energy Council [Nakićenović et al., 1998], the IPCC SRES, and the IPCC Third Assessment Report [Metz et al., 2001]. We use their analysis in order to define broader uncertainty ranges of future technology costs (see Appendix A for further details on cost and demand assumptions).

As noted earlier, all our scenarios consider a modest price for carbon, approximating that there will be some (but not drastic) efforts to limit climate change over the long term. The expected carbon price (and its PDF) was derived from a subset of 58 stabilization scenarios from the IPCC-AR4 scenario database [Hanaoka

\footnotetext{
${ }^{7}$ For further details of the B2 scenarios see also the IIASA GGI scenario database: http: //www.iiasa.ac.at/Research/ENE/GGIDB_index.html
} 
et al., 2006] with $\mathrm{CO}_{2}$-equivalent concentration targets of $650 \mathrm{ppmv}$ and higher. A lognormal distribution was fitted to this sample of carbon prices in the year 2100 (see Appendix A.3) and the resulting values were then propagated backwards to 2010 with the discount rate. This procedure results in a moderate expected carbon price of $4.6 \mathrm{US} \$ / \mathrm{tC}$ in 2010 which grows with the model's discount rate of $5 \%$ over time. The carbon price in later periods is e.g. $12.2 \mathrm{US} \$ / \mathrm{tC}$ in $2030,32.5 \mathrm{US} \$ / \mathrm{tC}$ in 2050 and $372 \mathrm{US} \$ / \mathrm{tC}$ in 2100.

\subsection{Stochastic Parameters}

We need to define uncertainties with appropriate assumptions about the shape, variance and correlation between different uncertain cost parameters.

Unlike in natural sciences, controlled experiments are unfortunately not available to define the shape of probability distribution functions of future technology costs. There is though some limited empirical evidence from time-series analysis of historical technology data (e.g. nuclear power generation [Koomey and Hultman, 2007]), which suggest the use of lognormal or similar distributions (e.g. Gamma), characterized by a tail on the upper side and a cut-off on the lower part of the costs. Similar to earlier stochastic analysis by for example Gritsevskyi and Nakićenović [2000] we thus apply lognormal distributions ${ }^{8}$ to all uncertain cost parameters where the expected values correspond to the deterministic $\operatorname{costs}^{9}$

Depending on which part of the technology costs are dominant, we either model (capacity-related) investment or (activity-related) variable operation and maintenance costs as uncertain parameters. For example, the variable costs of fossil fuel extraction as well as biomass production and nuclear fuel costs are modeled as uncertain parameters. For power generation, including carbon capture and storage (CCS) and liquid fuel production, investment costs typically dominate levelized production costs (excl. fuel costs) and are therefore modeled as uncertain. In contrast, for energy-saving options which operate on the level of conservation cost curves the cost of the activity is assumed to be uncertain.

We assume also that the cost uncertainty of technologies is increasing over time. For this purpose we use the future cost distributions from Nakicenovic and Riahi [2001] as a proxy to define the cost variance for individual technologies at the end of the time horizon. ${ }^{10}$ Figure 5 gives a schematic illustration of the increasing uncertainty over time (technical details of the implementation are given in Appendix A.2). Apart from the evolution of the expected value, Figure 1 also shows the 25th and 75th percentile (shaded area) as well as the 1st and 99th percentile of the distribution function. Given our approach, costs generally change more rapidly in the first decades and then converge towards their long-term value in the second half of the century. Perhaps, most importantly our implementation of uncertainty

\footnotetext{
${ }^{8}$ The choice of lognormal distributions for the costs corresponds to normally distributed growth rates of these.

${ }^{9}$ In total 32 cost parameters are treated as uncertain, 31 of which are technology-related and the $32 \mathrm{nd}$, the carbon price, is policy-related.

${ }^{10}$ The cost distributions are defined for the final year of the model's time horizon, i.e. 2100. To derive cost paths for the model's full time horizon $(2000-2100)$ we exponentially interpolate between the base year value in 2000 and the random parameter values in 2100 .
} 
considers not only the possibility of dropping costs, but also a long tail with small likelihoods of increasing costs as observed during the recent years.

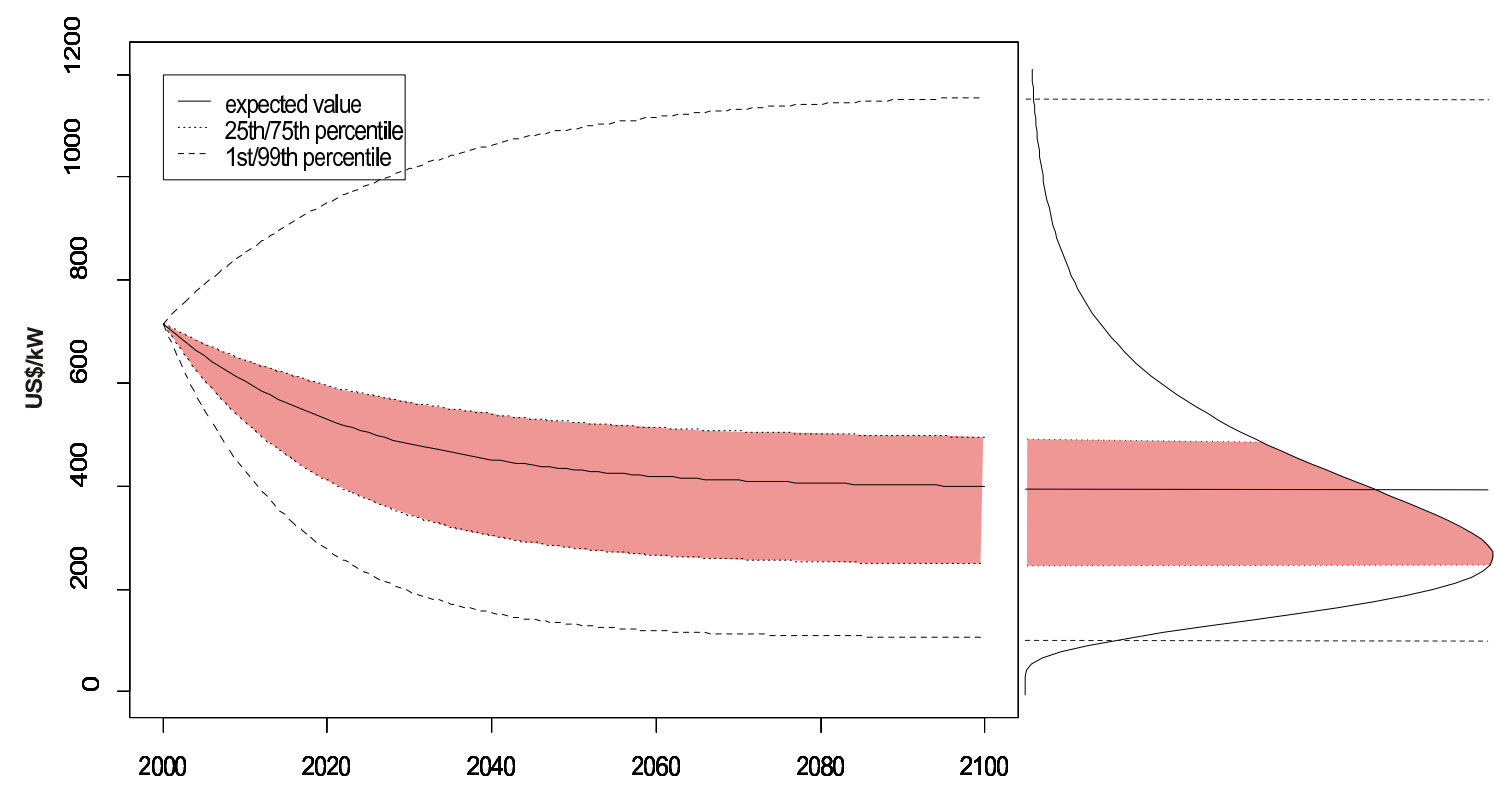

Figure 5: Illustration of cost interpolation procedure (left) and cost distribution in 2100 (right) for investment costs of a natural gas combined cycle power plant.

We distinguish three broader uncertainty categories for individual technologies: low uncertainty $\left(\sigma_{\text {low }}=0.15\right)$, medium uncertainty $\left(\sigma_{\text {med }}=0.3\right)$ and high uncertainty $\left(\sigma_{h i g h}=0.6\right)$. Following Nakicenovic and Riahi [2001], mature technologies with only small cost reduction potentials (e.g. coal power plant, oil refinery) exhibit low variance and are thus assigned to the lowest uncertainty category. Readily available technologies that have been deployed on a large scale, but are still expected to have significant cost reduction potential (e.g. gas combined cycle power plant) are grouped in the medium uncertainty category. In addition, also mature technologies where heterogeneity and local context adds to the cost uncertainty (e.g. hydro power, fossil fuel extraction, energy-saving measures) are assigned to the intermediate category. Finally, advanced technologies with potential for high cost reductions typically show a wide spread of cost assumptions across different scenarios (e.g. solar photovoltaics). These technologies are grouped with those that are affected by additional risks (e.g. acceptance problems of nuclear power) in the category with the highest uncertainty. The resulting classification of individual technologies are denoted in Figure 4 as small letters in the technology boxes $(\mathrm{l}=$ low, $\mathrm{m}=$ medium and $\mathrm{h}=$ high).

Many energy technologies share similar components (e.g. gas turbines in natural gas combined cycle and integrated coal gasification combined cycle power plants) or rely on identical technologies (e.g. exploration and drilling techniques for conventional oil and gas reserves). Hence, the future development of their costs and the associated diffusion process are not independent from each other [Kann and Weyant, 2000, p.36]. As illustrated earlier, this has major implications for hedging or diversification strategies. We thus explicitly include correlations among different uncertain parameters in our modeling framework. For some of the technologies data was avail- 
able from specific technology component analysis (electricity generation technologies [Kouvaritakis and Panos, 2005]) to derive the correlation coefficients. For others we rely on expert opinions. Similar to the uncertainty categories, we distinguish several levels of correlation, i.e. perfect $\left(\rho_{i j}=1\right)$, high $\left(\rho_{i j}=0.7\right)$, medium $\left(\rho_{i j}=0.35\right)$ and uncorrelated $\left(\rho_{i j}=0\right)$. A more detailed description of this procedure can be found in Appendix A.2.

\section{Results}

This section presents results of the global stochastic modeling framework. We analyze a series of model runs and compare scenario outcomes with and without consideration of uncertainties. By doing so we explore the main characteristics of least-cost risk hedging strategies and the extent to which the imputed risk of future uncertainties can be reduced, and at what costs. We are hence particularly interested in the relationship between the "risk premium" and avoided risk, including implications for the tail of the cost distribution. In addition, we analyze responses of the energy system with respect to the technology portfolio and investment patterns, as well as consequences for carbon emissions under uncertainty.

\subsection{Energy System Costs}

Our stochastic approach considers the uncertainty of future technology costs as well as of the carbon price. On an aggregated level these uncertainties translate into distinct future distributions for the total energy system costs, which critically depend on investment decisions and the type of technologies that become adopted. Comparisons of probability distributions of different energy deployment pathways are thus critically important for understanding the implied risk of different strategies.

A comparison of the probability density function (PDF) of the total energy system costs of two alternative development pathways, with and without considering uncertainty, is illustrated in Figure 6(a) - (d). The individual panels show discounted system costs over the century as well as for individual points in time (2030, 2050, and 2100). ${ }^{11}$ The deterministic solution's PDFs are shown in black whereas the PDFs of our stochastic model, assuming a risk premium of 1\%, are shown in red.

In the deterministic model uncertainty is ignored in the decision process and system costs are minimized based on expected values of all input parameters. The resulting distribution of energy system costs is relatively wide, including high-cost tails with comparatively higher probability of very costly outcomes. In contrast, the PDFs resulting from the stochastic solution with a risk premium of $1 \%$ are more centered around their expected value than the deterministic ones. While this tendency increases over time as uncertainties grow towards the end of the century

\footnotetext{
${ }^{11}$ The energy system cost PDFs are generated by propagating the joint input distributions through the model, given a fixed solution. Technically speaking, the $N=20000$ realizations of uncertain cost parameters are multiplied with the deterministic and stochastic solution vectors respectively, thus obtaining 20000 objective function values. A kernel density estimate is then used to generate the PDFs in Figure 6.
} 
(see Section 4.2), the distributions clearly show increasing confidence that future system costs will be closer to the expected values.

By construction the expected value of system costs, indicated by the red vertical lines in all subfigures, is shifted by $1 \%$ to the right indicating the additional costs (or hedging investments) that were spend to reduce uncertainties and their imputed risk. Consequences of this investment are visible in the tails of the cost distributions, represented by the 99th percentiles in Figure 6 which are shifted towards the expected value, implying significantly reduced risk of unfavorable outcomes with extreme costs. Remarkably, the shaving of the tales has occurred even though we employ upper mean absolute deviation as our default risk measure which puts uniform emphasis on all parts of the distribution exceeding the expected value and not only the tails (see also Section 2.2). This development needs thus be seen as an endogenous response driven by the characteristics of energy system uncertainties.

This effect is most pronounced in the long term. For example, by 2100 total costs in the deterministic case are twice as high as the expected value at the 99th percentile of the distribution (see Figure $6(\mathrm{~d})$ ). With additional hedging investments of just $1 \%$ the 99th percentile's value is reduced by about $60 \%$ in relation to the expected value. Or in other words, hedging investments of just about 100 billion US $\$$ have acted as a leverage to reduce the risk at the 99 th percentile by more than 6 trillion US\$. This behavior nicely illustrates the trade-off between expected value costs and risk of severely underestimating future costs.

As a result of discounting with $5 \%$ the PDF of total discounted system costs (Figure 6(a)) is dominated by the relatively narrow near-term distributions and exhibits a shape which is similar to the PDFs of 2030 and 2050, but much narrower than the $2100 \mathrm{PDF}$ which is suppressed by a factor of $\sim 80$ in comparison with the 2010 PDF due to discounting.

The above calculations assume a risk or insurance premium of $1 \%$, hence limiting the additional hedging investments to $1 \%$ of total systems costs of the deterministic case. It needs to be emphasized, however, that in the "real world" the risk premium is dependent on the risk attitude of the decision maker, and is therefore a policy variable. A quantitative analysis of the trade-off between the costs of hedging (i.e. the risk premium $f$ ) and the resulting benefits in terms of reduced risk is nevertheless central for providing guidelines and to understand the order of magnitude of this trade-off. Figure 7 thus shows the relationship between increasing risk premium and the resulting benefits in terms of reduced risks through changes in the distribution of future system costs. We specifically focus on the 80th to the 99th percentile of the cost distribution, with the solid lines showing how these quantiles change as a function of the risk premium $f$ in case of upper mean absolute deviation and the dashed lines showing the relationship for the case of semi-variance. As clearly illustrated by Figure 7, increasing willingness to invest into the risk premium is generally resulting in reduced risk of high energy system costs. The marginal benefits of hedging investments, however, decrease with increasing risk premium $f-$ a clear indication of decreasing returns of scale at high premiums. How the different quantiles perform as a function of the risk premium also depends on the employed risk measure. The linear risk measure (upper mean absolute deviation) reduces the 80th and 90th percentiles stronger than the quadratic one (semi-variance) whereas 

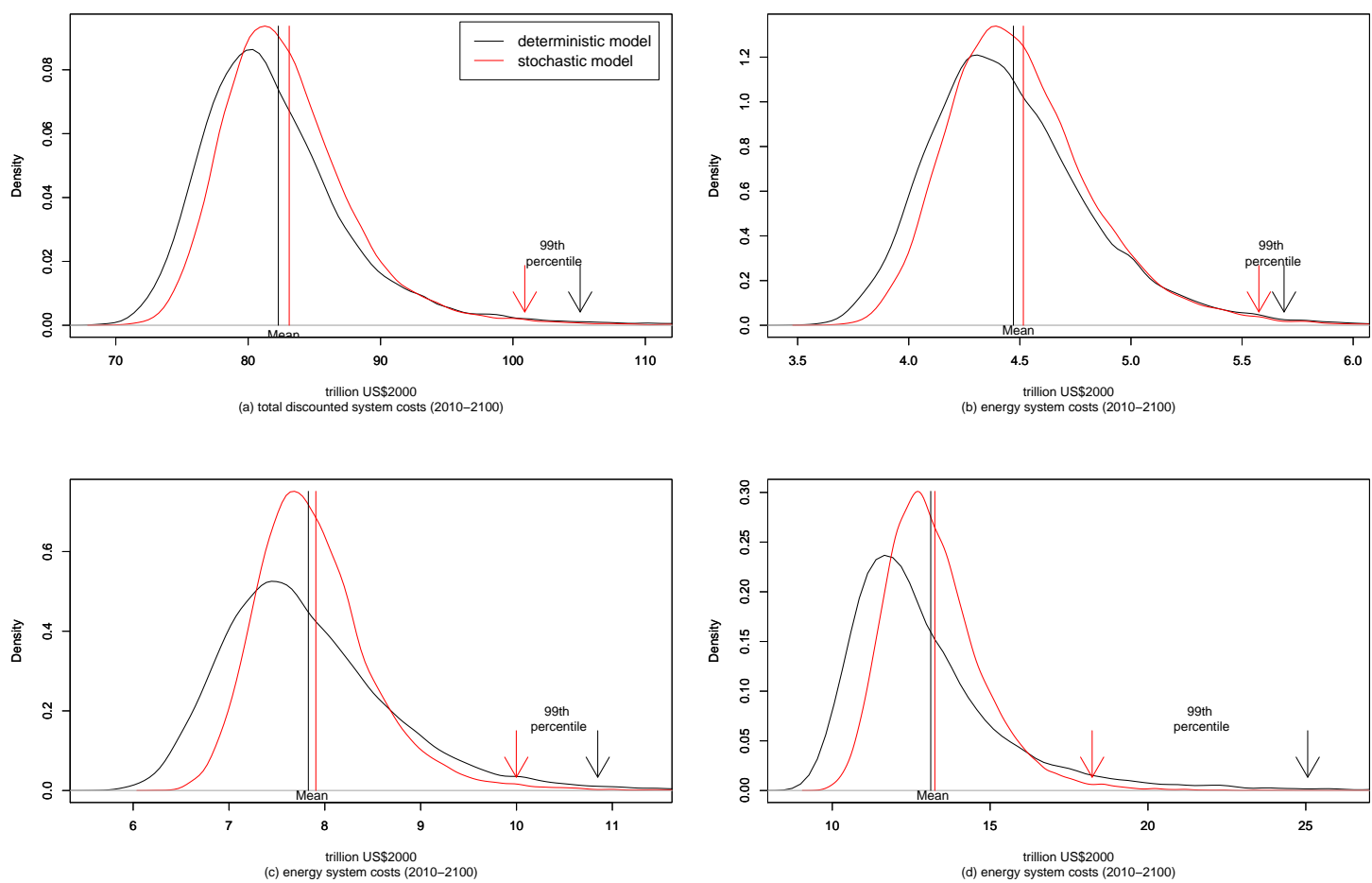

Figure 6: Probability density functions of future energy systems costs. Deterministic model without uncertainty (black) and stochastic model results assuming a risk premium of $1 \%$ (red): (a) total discounted system costs $(2010-2100)$, (b) system costs in 2030, (c) in 2050 and (d) in 2100.

the situation is the opposite for the 95th and 99th percentiles. As expected, the quadratic risk measure puts a higher emphasize on reducing the impact of the extreme tail events and therefore the 99th percentile is reduced strongest, followed by the 95th, 90th and the 80th percentiles in relative terms.

Regarding the choice of the risk premium, Figure 7 clearly shows that $1 \%$ is in the range where the marginal returns of the hedging investments become relatively saturated - as indicated by the flattening curves for most quantiles in the figure. We therefore select in the sequel a risk premium of $f=1 \%$ as our central case, but will continue to show the sensitivity of the results for alternative risk premiums if necessary.

\subsection{Primary Energy Supply}

The development of total primary energy supply (TPES), resulting from different assumptions about uncertainty, are shown in Figure 8. Panel (a) displays the development in the deterministic case without any uncertainty, while panel (b) to (d) illustrate the impact of considering either only technology-related uncertainties (b), only carbon price uncertainties (c), and finally taking both carbon and technology uncertainties into account simultaneously (d).

Comparing panels (a) and (b) of Figure 8 reveals the main responses of the en- 


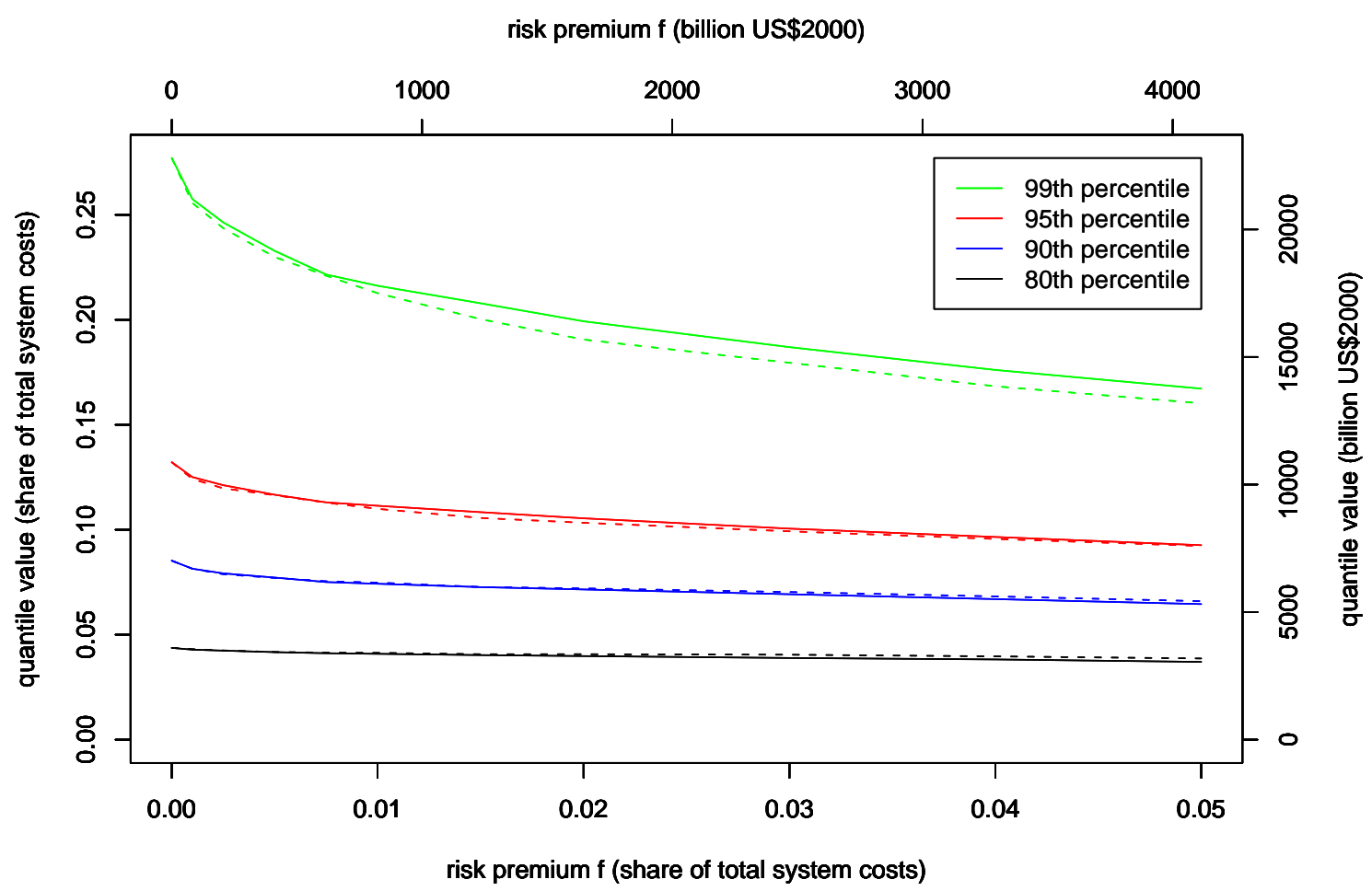

Figure 7: Trade-off between expected total system costs and risk for linear (solid lines) and quadratic risk measure (dashed lines).

ergy system due to technology uncertainty. ${ }^{12}$ An important characteristic of the deterministic energy system is that the lack of uncertainty results in the sequential deployment of first the cheap options until they are exhausted, followed later by an almost instant switch to new technologies or resources. By contrast hedging against technology uncertainty results in the comparatively early introduction of new and advanced alternatives. This is e.g. visible in the deployment schedules of oil resources, where under technology uncertainty depletion of conventional oil (characterized by relatively lower uncertainty) is delayed, while unconventional oil is introduced earlier in time (compared to the deterministic case). The result is a mixture of conventional and unconventional extraction in order to increase the resilience of the system against the possibility that unconventional oil might not become available at the expected price. The same holds for unconventional gas, but also for other advanced technologies, which deploy comparatively earlier in case of considering uncertainty. In the medium- to long-term this results in a more diverse technology portfolio, which we will discuss in some detail in Section 5.4 on diversification. Perhaps, worth noting is also the revival of coal under technology uncertainty, which is a direct result of the relatively lower uncertainty of coal occurrences and electricity generation technologies, which push coal tentatively back into the system around mid century. In the latter half of the century, coal becomes less deployed due to the increasing carbon price over time.

Comparing Panels (a) and (c) illustrates the impact of carbon price uncertainty.

\footnotetext{
${ }^{12}$ It is important to recall that both panels consider a modest expected value carbon price.
} 

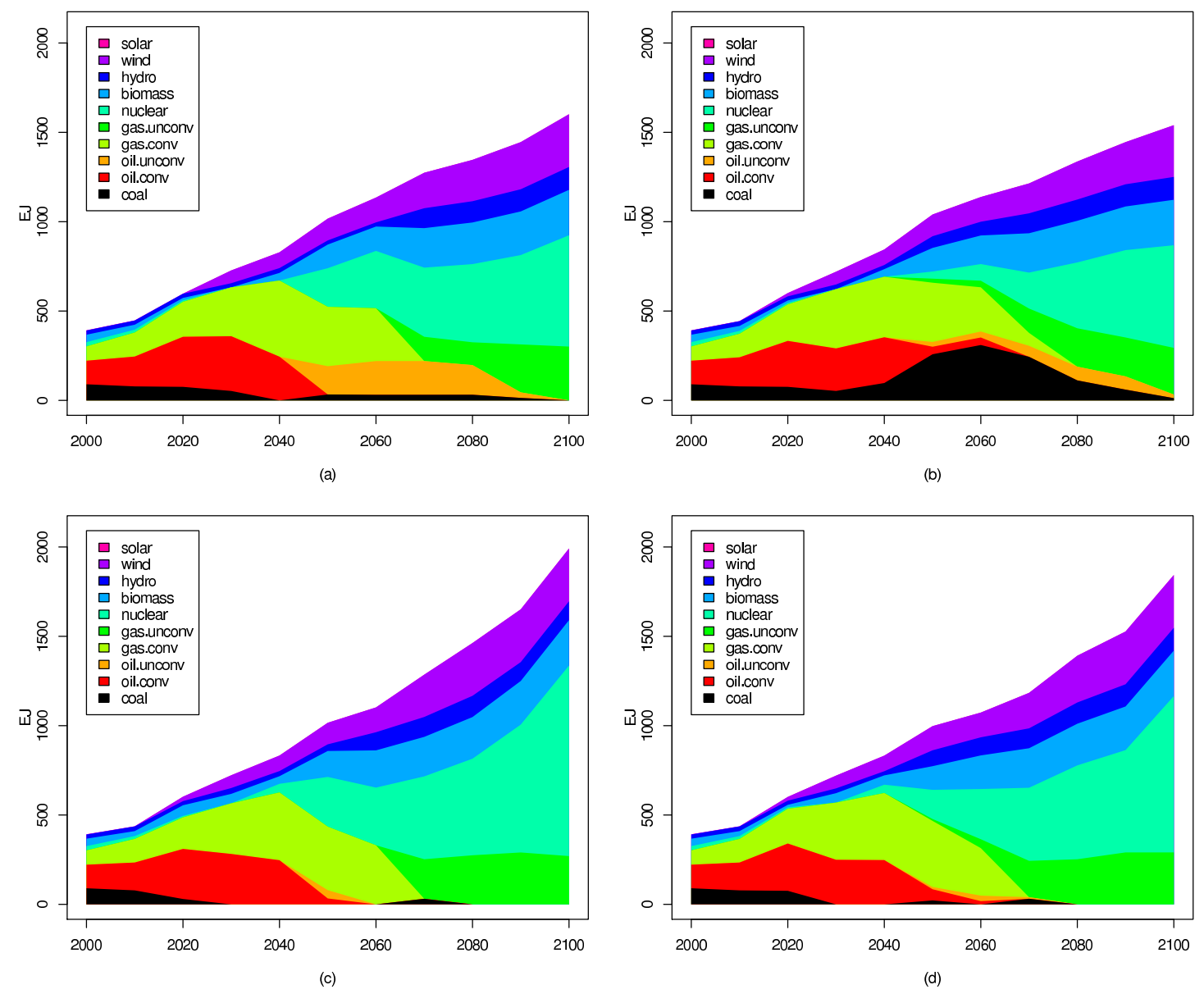

Figure 8: TPES in the (a) deterministic case, (b) technology uncertainties only case, (c) carbon price uncertainty only case, and (d) technology and carbon price uncertainties case

It needs to be noted that the case with carbon price only uncertainty corresponds in theory to an alternative deterministic model run with relatively higher carbon price, since the risk term penalizes carbon emissions only, and all other energy system aspects are deterministic. There is thus no trade-off between different types of uncertainties as in the case of technology uncertainty shown in Panel (b). It is therefore not surprising that the scenario with uncertain carbon prices features (compared to the deterministic case) primarily a further reduction of the deployment of carbon-intensive technologies (and emissions). Diversification as observed under technology uncertainty is thus lacking in this setup.

Note also the increase in total primary energy use, which is primarily a result of decarbonization of the end-use sectors by a fuel switch to hydrogen whose production is quite energy-intensive, in particular because we have adopted fossil fuel equivalent TPES accounting method for renewable and nuclear energy ${ }^{13}$.

Comparing all three stochastic panels (b) to (d) with the deterministic panel (a) we recognize quite different changes in quantity and structure of TPES. Whereas

\footnotetext{
${ }^{13}$ Each unit of electricity generated from renewable and nuclear energy contributes with 2.56 units to TPES corresponding to a conversion efficiency of $39 \%$.
} 
in the technology uncertainties only case (b) an increased use of coal as well as a diversification of TPES is observed, the carbon price uncertainty only case (c) mainly shows more pronounced decarbonization and an increase of TPES towards the end of the century with no revival of coal. The results of the combined technology and carbon price uncertainty run in panel (d) combines some of these effects and is characterized by both diversification and decarbonization, but also increased TPES towards the end of the century.

In summary, we thus conclude that it is important to take a holistic view and consider both technology- and policy-related uncertainties simultaneously. Only including one of them leads to either diversification or hedging against possibly high carbon prices with distinctly different technology portfolios. Incomprehensive account of uncertainty may thus lead to biased policy recommendations.

\section{3 $\quad \mathrm{CO}_{2}$ Emissions}

As mentioned earlier, our scenarios assume an expected value for the carbon price of about $4.6 \mathrm{US} \$ / \mathrm{tC}$ in 2010 which increases with the discount rate to about 370 $\mathrm{US} \$ / \mathrm{tC}$ in 2100. This corresponds to the mean over all scenarios in the IPCC scenario database [Hanaoka et al., 2006] with $\mathrm{CO}_{2}$-equivalent concentration stabilization targets of $650 \mathrm{ppmv}$ and above. The deterministic implementation of this carbon price trajectory results in our modeling framework in cumulative $\mathrm{CO}_{2}$ emissions of $\sim 880 \mathrm{GtC}$ over the course of the century, corresponding to $\mathrm{CO}_{2}$ concentrations around $530 \mathrm{ppm}$ towards 2100. Considering also non- $\mathrm{CO}_{2}$ emissions, based on the scenario classification from Chapter 3 of the IPCC Fourth Assessment Report [Fisher et al., 2007], this would correspond to about 650 ppmv $\mathrm{CO}_{2}$-equivalent concentrations. This result, although not surprising, illustrates that our modeling approach leads to very similar results than other deterministic models assessed by the IPCC.

Considering the uncertainty of the carbon price, however, we observe significant changes of the emissions pathway towards more stringent mitigation. This is particularly due to the lognormal distribution of the carbon price, including low probability events in the tail with much higher carbon prices of several thousand US\$/tC. Therefore, in the stochastic cases hedging against the tail of high carbon prices becomes a major motivation to reduce carbon emissions, even if additional technology uncertainty is considered. This response to uncertainty has also been observed in previous studies, such as [Manne and Richels, 1992; Pizer, 1999; Yohe et al., 2004]. While we derive the same conclusion, the reason for the response is different. Both Manne and Richels [1992] and Yohe et al. [2004] conclude that relatively lower emissions would be rectified due to the uncertainty of climate change damages (i.e. uncertainties in the response of the physical climate system to an increase in GHG emissions), whereas our analysis suggests lower emissions because of the economic risk of uncertain carbon prices.

We find further that the stringency of mitigation is critically dependent on the risk premium. The relationship between the risk premium and annual carbon emissions and resulting atmospheric $\mathrm{CO}_{2}$ concentrations are summarized in Figure $9 .{ }^{14}$

\footnotetext{
${ }^{14}$ The annual carbon emissions in Figure $9(\mathrm{a})$ are a direct model output whereas the $\mathrm{CO}_{2}$ con-
} 

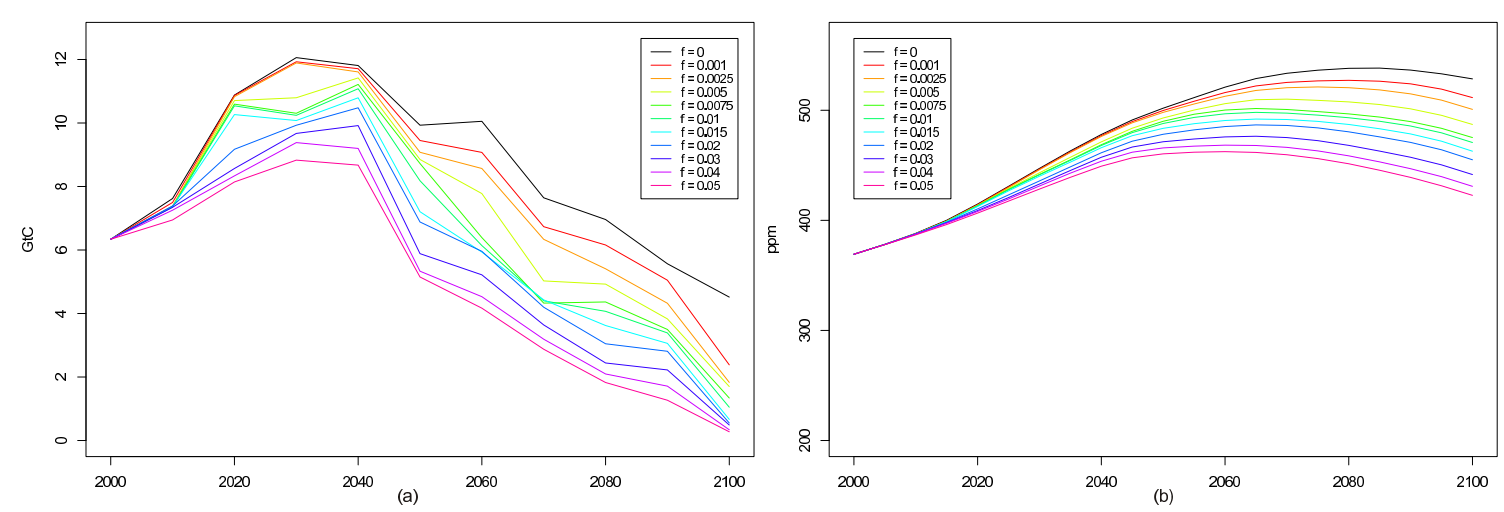

Figure 9: (a) Annual energy-related carbon emissions in GtC and (b) atmospheric $\mathrm{CO}_{2}$ concentrations in ppm as a function of the risk premium $f$

We observe that already very small additional hedging investments of only $0.1 \%$ result in a reduction of cumulative emissions by $50 \mathrm{GtC}$ or $5.5 \%$ in comparison to the deterministic case. This corresponds to a $\mathrm{CO}_{2}$ stabilization level of about 515 ppm. In our standard case with a risk premium of $1 \%$, cumulative emissions are approximately reduced by an additional $22 \%(\sim 690 \mathrm{GtC})$ for the linear risk measure (upper mean absolute deviation), corresponding to a further reduction of the $\mathrm{CO}_{2}$ stabilization level to $\sim 480 \mathrm{ppm}$. The impact of the distribution's tail is more pronounced by the quadratic and CVaR risk measures. Thus, in the quadratic case emissions are reduced by another $2 \%$-points, to about $670 \mathrm{GtC}$ in comparison with the linear risk measure. The $95 \%$-CVaR risk measure even results in cumulative emissions of $\sim 620 \mathrm{GtC}$ reaching a $\mathrm{CO}_{2}$ concentration level of close to $460 \mathrm{ppm}$ $\mathrm{CO}_{2}$ by the end of the century. For higher risk premiums even more effort is put into carbon abatement to limit the impacts of eventually high carbon prices, e.g. at $f=3 \%$ we find a reduction in excess of one third (580 GtC, $450 \mathrm{ppm}$ ) in comparison with the deterministic optimization and at $f=5 \%$ cumulative emission reductions constitute even more than 40\% (510 GtC, $430 \mathrm{ppm}$ ).

The peaking year of energy-related $\mathrm{CO}_{2}$ emissions is only marginally affected by the risk premium and varies just between 2030 and 2040. However, the magnitude of the emission peak changes considerably from $12 \mathrm{GtC}$ in the deterministic case $(f=0)$ to $8.8 \mathrm{GtC}$ at a risk premium of $f=5 \%$. The impact on near-term emissions is relatively smaller in our standard case with a risk premium of $1 \%$, where emissions are about $10 \mathrm{GtC}$ around 2030, and stay relatively unaffected until 2020 , because of the energy system's inertia (see Figure 9).

\subsection{Diversification}

As discussed in the context of the 3-technology model in Section 3, but also in the previous paragraphs, diversification may serve as a possible hedging strategy to increase resilience of a system. While we are focusing in this section particularly

centrations in the atmosphere in Figure 9(b) are calculated with the climate model MagiCC 4.1 [Wigley, 2003]. As our model calculates only energy-related emissions, we added for this purpose non-energy-related $\mathrm{CO}_{2}$ emissions (e.g. land-use change, cement production, gas flaring) from a 670 ppmv stabilization scenario developed at IIASA [Riahi et al., 2007]. 
on the diversification within the electricity sector, it needs to be stressed that the energy system is more complex, and diversification may also occur as a result of shifting investments between different sectors. These aspects are discussed later in Section 5.5, which is focusing on the investment patterns under uncertainty.

In order to measure diversity, we employ an integrated multi-criteria diversity index developed by Stirling [1998], which is based on distance metrics and will be referred to in the following as the Stirling index ${ }^{15}$. We are in particular interested in the relationship between the Stirling index and the risk premium, and to which extent increasing risk aversion is triggering diversity as a response to uncertainty.

For this purpose, Figures 10 (a) and (b) display the electricity generation portfolio's dependence on the risk premium $f$ in 2030 and 2050 respectively. In addition to the technology shares in electricity generation, the relationship between the Stirling index and the risk premium is shown on the right axes of the graphs. As can be seen from Figures 10(a) and (b) the Stirling index is generally increasing at higher risk premiums, but the behavior is quite different in 2030 and 2050.

Fossil power generation from natural gas dominates electricity generation in the short- to medium-term as is evident from its high share in 2030 (Figure 10(a)). In the deterministic case hydro and wind are the only other two technologies contributing to electricity generation. At risk premiums below $2 \%$ this situation only marginally changes towards a larger share of hydro power plants. Above $2 \%$ nuclear power comes in as a fourth option, resulting in a significant increase of the Stirling index. This situation indicates that the gap in levelized electricity generation costs between natural gas and nuclear is substantial $(0.96 \mathrm{ct} / \mathrm{kWh}$ which corresponds to $\sim 26 \%$ higher costs for nuclear) which requires a relatively high risk premium of $2 \%$ to bring in this alternative. Coal power generation is phased out until 2030 as a result of a moderate carbon price and the uncertainties that come along with it. ${ }^{16}$
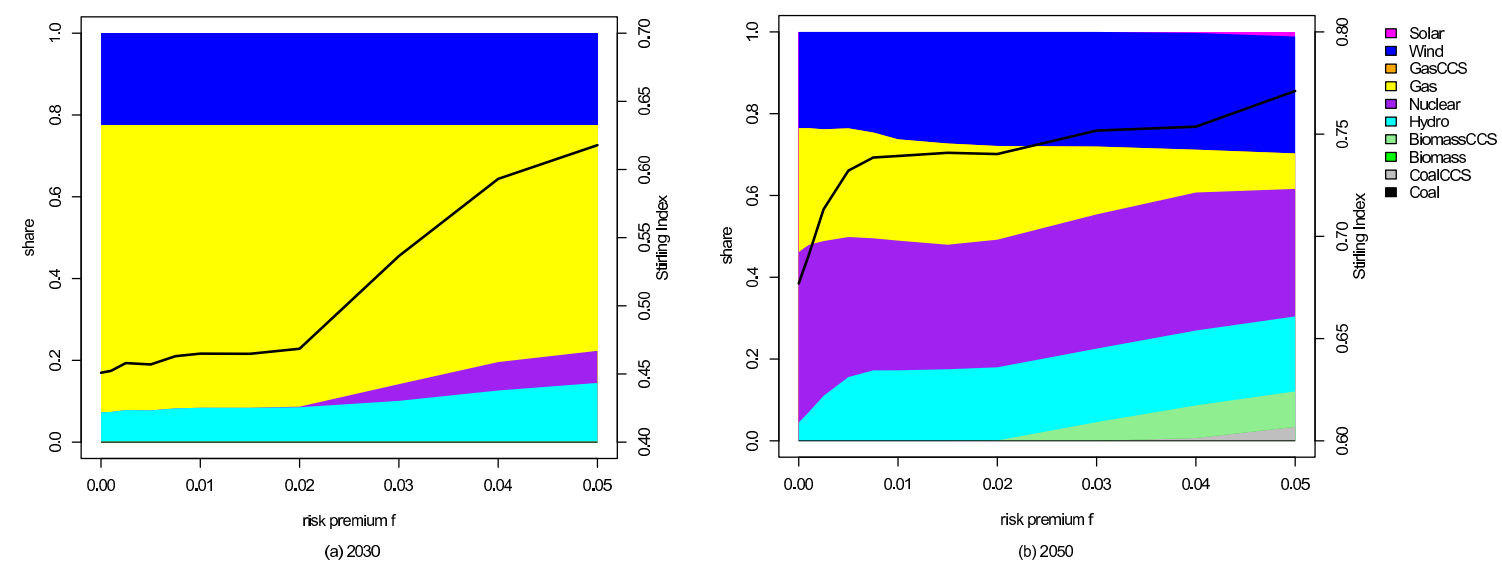

Figure 10: Technology shares in electricity generation and corresponding Stirling index in (a) 2030 and (b) 2050 as a function of the risk premium $f$.

\footnotetext{
${ }^{15}$ The index is defined as $\mathbf{M}=\sum_{i j} d_{i j} p_{i} p_{j}$, where $p_{i}$ is technology $i$ 's share of electricity generation and $d_{i j}$ the distance in Euclidean disparity space between technology $i$ and $j$ [Stirling, 1998][chp. 3.2]. For the graphs a distance of 0.5 between fossil energy technologies (coal and gas) is used whereas for all other technologies we assume a distance of 1 .

${ }^{16}$ We assume on average a lifetime of 30 years for fossil power plants. Therefore by 2030 all power plants that were built in the base year 2000 reach the end of their lifetime.
} 
In 2050 the deterministic electricity generation portfolio features four technologies, namely gas, nuclear, hydro and wind that contribute to electricity generation. Already at relatively low risk premiums of less than $1 \%$ the share of hydro more than triples at the cost of gas and nuclear power generation, resulting in a noticeably higher Stirling index. The reason for this early diversification is that levelized electricity generation costs are very close for these three technologies with hydro only being some $8 \%$ and $6 \%$ more expensive than gas and nuclear respectively. With further increasing risk premium the technology portfolio grows to seven technologies with biomass CCS power plant, coal CCS power plant and solar PV joining in. In addition, the shares are much more evenly distributed, such that at $f=5 \%$ no technology supplies more than $31 \%$ of total electricity in comparison to almost $42 \%$ in the deterministic model run. This is an illustration of the previously cited Don't put all your eggs in one basket rule. The observed diversification is though significantly stronger by 2050 compared to 2030, due to the short-term inertia of the system against rapid structural changes.

It has to be emphasized that in contrast to modeling frameworks that explicitly aim at diversification as an objective (e.g. [Stirling, 1994]) in our modeling framework diversification is an endogenous result driven by the aim to reduce risk. The extent of diversification is, however, critically dependent on the nature of the system and the dependence structure of joint input distributions which we have assumed (see Appendix A.2). Our sensitivity analysis of the same scenarios indicate that in absence of any correlation between the costs of power generation technologies diversification would be significantly more pronounced.

\subsection{Energy-related Investments}

We finally review the implications of the risk-hedging strategies for energy-related investments. Our systems engineering perspective permits us to explore shifts of investment between various technology clusters in fuel extraction, electric, nonelectric (liquid fuels), and the energy end-use sectors.

The cumulative energy system investments between 2010 and 2050 are summarized in Figure 11. Although we are dealing with a moderate stabilization scenario ( 690 ppmv $\mathrm{CO}_{2}$-equivalent concentration in the deterministic case), investments into fossil fuel technologies still dominate the first half of the century. In particular upstream investments, but also electricity generation and liquid fuel production are characterized by high shares of fossil fuels, particularly in absence of uncertainty. This situation changes in the stochastic cases with increasing shares of investments into low-carbon options such as biomass, nuclear and renewable electricity generation and synthetic fuels. In addition, increased efforts to improve energy efficiency in the end-use sectors become a more important factor in the stochastic cases, where the strongest increase occurs at risk premiums higher than $1 \%$. Most of these efficiency improvements take place in the non-electric and transport end-use sectors, because decarbonization is typically more costly in these sectors than e.g. for electricity.

Total energy-related investments in the deterministic case are estimated to be around 49 trillion US\$2000 between 2010 and 2050. Additional investments into risk-hedging range between $7 \%$ and $30 \%$, corresponding to a total of 52 and 64 


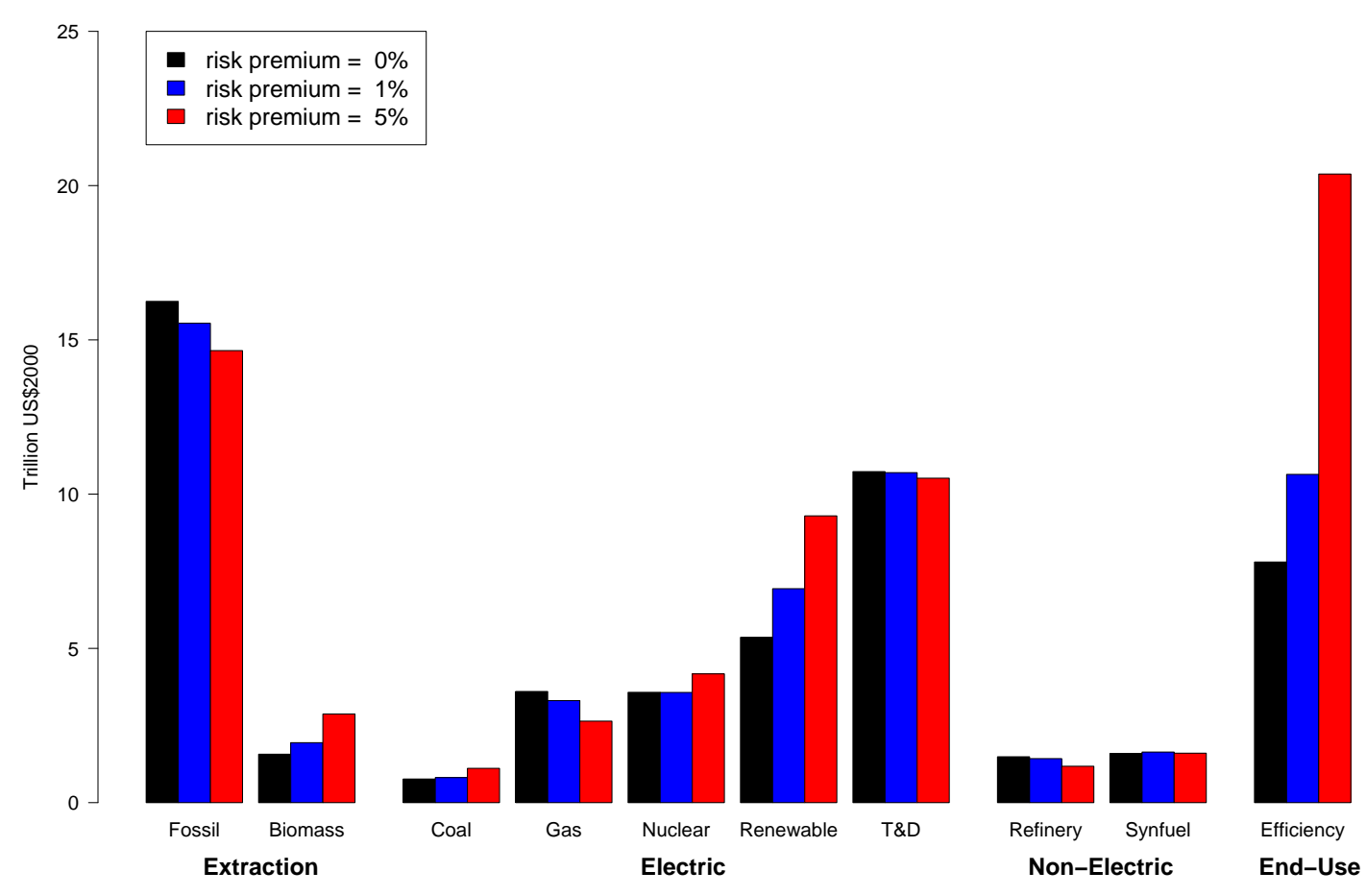

Figure 11: Cumulative energy system investments for the period 2010 - 2050 in different sectors as a function of the risk premium

trillion US\$ in the cases with $1 \%$ and $5 \%$ risk premium respectively. Despite the comparatively modest increase of total costs, which is determined by the risk premiums, a significant increase in investments is required. Along with the increase of the total energy investments, we observe a considerable reallocation of investments among the different sectors of the energy system, most notably from the supply-side sectors to the end-use sectors, but also from fossil to renewable technology clusters. For example, the reallocation of investments between the four major sectors indicated in Figure 11 (i.e. resource extraction, electricity generation, non-electric sector and end-use) comprises $4.5 \%$ and $15 \%$ of total energy-related investments between 2010 and 2050 under the $1 \%$ and the $5 \%$ risk premium respectively. These numbers increase further if reallocation of investment within the four major sectors, e.g. from fossil electricity generation towards renewables, are taken into account. It is interesting to note that the reallocation of investments becomes increasingly important for the lowest risk premiums of $1 \%$ and below, simply because the total increase of energy system expenditures, and therefore also investments, is tightly constrained by the risk premium. For these cases, the reallocation effect is comparable to the absolute increase of energy investments.

In terms of energy expenditures, i.e. in addition to investments also including operation and maintenance costs, the reallocation effect is much more drastic. We find that the reallocation of energy-related expenditures is up to a factor of 10 higher than the total increase in expenditures in the case of ver low risk premiums. In Section 5.1 it was shown that more robust solutions can be obtained even at very low hedging costs. However, the dominance of redistribution of sectoral investments and 
expenditures over the actual increase in costs, in particular at low risk premiums, illustrates that hedging results in significantly different investment patterns in comparison with the deterministic least expected cost solution. Therefore, it is not so much the total costs of hedging against technology- and carbon price uncertainties that need to be in the focus of attention, but rather how investments are allocated within the energy system ${ }^{17}$, with major implications also for the appropriate portfolio of up-front R\&D expenditures.

\section{Summary and Conclusions}

Traditional deterministic energy models without an endogenous representation of uncertainty favor cost-optimal investments into a limited set of technologies that are expected to perform best in the future. Exploring the uncertainty of future energy systems costs, however, we find that such strategies can be very costly. This is in particular due to the nature of imputed energy systems uncertainties, characterized by long tails and the possibility of very high costs in case future uncertainties are resolved in an unfavorable direction.

In this paper we thus presented a new modeling framework of the global energy system, which combines traditional elements of systems engineering modeling approaches with salient features of a risk management perspective. Employing stochastic optimization techniques with fully endogenous representation of uncertain costs and associated risks along the energy chain, including extraction and conversion technologies as well as demand-side management costs, permitted us to identify future development pathways that are cost effective not only from todays perspective and expectations, but factor in also the imputed risk of uncertainty.

Through a series of sensitivity analysis we identify characteristics of risk hedging strategies that are adapted to considerably reduce future risks and are hence robust against a wide range of future uncertainties. We observe significant changes in response to energy system and carbon price uncertainties with major implications for the expected energy system costs, timing of investments, the choice of technology as well as resulting emission levels.

Firstly, we find that hedging strategies under uncertainty are characterized by higher short- to medium-term investments into advanced technologies, including earlier deployment of renewables, but also exploration of unconventional natural gas resources. Our results illustrate that while in absence of uncertainty it seems to be cost-effective to postpone investments into new alternatives in order to maximize profits from available low-cost options early on; a more comprehensive view of the future including the uncertainty that new options might not become available at the expected costs imposes long-term deployment risks, and thus triggers early up-front investments into niche markets and demonstration plants.

Secondly, we find that $\mathrm{CO}_{2}$ emission reductions to be much more pronounced under uncertainty. This response to uncertainty has been observed in previous studies, such as Manne and Richels [1992]; Yohe et al. [2004]. While we derive the

\footnotetext{
${ }^{17}$ From a more technical perspective this illustrates that quasi-degeneration is an important problem in modeling, i.e. quite different solutions can be accommodated within very small variations of the objective function value of optimization models.
} 
same conclusion, the reason for the response is different. Yohe et al. [2004] conclude that relatively lower emissions would be rectified due to the uncertainty of climate change damages (i.e. uncertainties in the response of the physical climate system to an increase in GHG emissions), our analysis suggests lower emissions because of the economic risk of uncertain carbon prices and technology costs.

Thirdly, our analysis suggests a considerable diversification of the technology portfolio under uncertainty. Diversification helps not only to reduce the "average risk", but results in significant reduction of the risk of high impact tail events. In our analysis, for example, a modest risk premium of about one percent of total energy expenditures reduces the value of the 99th percentile by up to a factor of two relative to the expected value expenditures, thus reducing the risk of large losses significantly. This conclusion has important implications for energy and climate policy, emphasizing the risk of unbalanced $R \& D$ portfolios or picking winners at a premature stage, and thus focusing on a too narrow policy portfolio.

With respect to costs, we find that modest risk premiums (or hedging investments) can significantly reduce the vulnerability of the energy system against the associated uncertainties. The extent of early investments, diversification and emissions reductions, however, depends on the risk premium that decision makers are willing to pay to respond to prevailing uncertainties. In other words, our modeling framework helps to understand how much risk can be avoided through which mechanisms and at what costs. How much risk needs to be avoided is though dependent on the risk aversion of the society by large or decision makers in the respective sectors - and remains thus one of the key policy variables.

\section{References}

Beale, E. M. L., 1955. On minimizing a convex function subject to linear inequalities. Journal of the Royal Statistical Society. Series B (Methodological) 17 (2), $173-184$.

Carnell, R., 2006. lhs: Latin Hypercube Samples. R package version 0.3.

Dantzig, G. B., 1955. Linear programming under uncertainty. Management Science 1, 197-206.

de Vries, B. J. M., van Vuuren, D. P., Hoogwijk, M. M., 2007. Renewable energy sources: Their global potential for the first-half of the 21st century at a global level: An integrated approach. Energy Policy 35 (4), 2590-2610.

Dessai, S., Hulme, M., 2007. Assessing the robustness of adaptation decisions to climate change uncertainties: A case study on water resources management in the east of england. Global Environmental Change 17 (1), 59-72.

Ermoliev, Y., Wets, R. J.-B. (Eds.), 1988. Numerical Techniques for stochastic optimization. Vol. 10 of Springer Series in Computational Mathematics. SpringerVerlag, Berlin. 
Fisher, B., Nakicenovic, N., Alfsen, K., Morlot, J. C., Chesnaye, F. d. 1., Hourcade, J.-C., Jiang, K., Kainuma, M., Rovere, E. L., Matysek, A., Rana, A., Riahi, K., Richels, R., Rose, S., Vuuren, D. v., Warren, R., 2007. Issues related to mitigation in the long term context. In: Metz, B., Davidson, O., Bosch, P., Dave, R., Meyer, L. (Eds.), Climate Change 2007: Mitigation. Contribution of Working Group III to the Fourth Assessment Report of the Inter-governmental Panel on Climate Change. Cambridge University Press, Cambridge, pp. 169-250.

Gritsevskyi, A., Nakićenović, N., 2000. Modeling uncertainty of induced technological change. Energy Policy 28, 907-921.

Grübler, A., Gritsevskyi, A., 2002. A model of endogenous technological change through uncertain returns on innovation. In: Grübler, A., Nakićenović, N., Nordhaus, W. (Eds.), Technological Change and the Environment. Resources for the Future Press, Washington DC.

Grübler, A., Nakicenovic, N., Riahi, K., Wagner, F., Fischer, G., Keppo, I., Obersteiner, M., O’Neill, B., Rao, S., Tubiello, F., 2007. Integrated assessment of uncertainties in greenhouse gas emissions and their mitigation: Introduction and overview. Technological Forecasting and Social Change 74 (7), 873-886.

Hanaoka, T., Kawase, R., Kainuma, M., Matsuoka, Y., Ishii, H., Oka, K., 1 June 2007 2006. Greenhouse gas emissions scenarios database and regional mitigation analysis. Tech. rep., National Institute of Environmental Studies.

IIASA GGI, 2007. IIASA GGI scenario database.

URL http://www.iiasa.ac.at/Research/ENE/GGIDB_index.html

Iman, R., Conover, W., 1982. A distribution-free approach to including rank correlation among input variables. Communications in Statistics B 11, 311-334.

Iman, R. L., Conover, W. J., 1980. Small sample sensitivity analysis techniques for computer models with an application to risk assessment. Communications in Statistics - Theory and Methods 9 (17), 1749 - 1842.

Kann, A., Weyant, J., 2000. Approaches for performing uncertainty analysis in largescale energy/economic policy models. Environmental Modeling and Assessment 5 (1), 29-46.

Kanudia, A., Loulou, R., 1998. Robust responses to climate change via stochastic MARKAL: The case of Québec. European Journal of Operational Research 106, 15-30.

Koomey, J., Hultman, N. E., 2007. A reactor-level analysis of busbar costs for us nuclear plants, 1970-2005. Energy Policy 35 (11), 5630-5642.

Kouvaritakis, N., Panos, V., 4 March 2005 2005. Modelling the two factor learning curve equations - guidelines on implementation. Tech. rep., E3M Lab, School of Electrical and Computer Engineering, National Technical University of Athens. 
Krey, V., Martinsen, D., Wagner, H.-J., 2007. Effects of stochastic energy prices on long-term energy-economic scenarios. Energy 32 (12), 2340-2349.

Lempert, R. J., Groves, D. G., Popper, S. W., Bankes, S. C., 2006. A general, analytic method for generating robust strategies and narrative scenarios. Management Science 52 (4), 514-528, cited By (since 1996): 14 Export Date: 6 July 2009 Source: Scopus.

Loulou, R., Kanudia, A., 1999. Minimax regret strategies for greenhouse gas abatement: Methodology and application. Operations Research Letters 25 (5), 219-230.

Loulou, R., Labriet, M., Kanudia, A., 2009. Deterministic and stochastic analysis of alternative climate targets under differentiated cooperation regimes. Energy Economics In Press, Accepted Manuscript, doi: DOI: 10.1016/j.eneco.2009.06.012.

Manne, A., 1996. Hedging strategies for global carbon dioxide abatement: A summary of poll results emf 14 subgroup - analysis for decision making under uncertainty. In: Nakicenovic, N., Nordhaus, W. D., Richels, R., Toth, F. L. (Eds.), Climate Change: Integrating Science, Economics and Policy. Vol. CP96-1 of Conference Proceedings. International Institute for Applied Systems Analysis, Laxenburg, pp. 207-228.

Manne, A. S., Richels, R. G., 1992. Buying Greenhouse Insurance: The Economic Costs of Carbon Dioxide Emission Limits. The MIT Press, Cambridge, Massachusetts.

Marti, K., Ermoliev, Y., Pflug, G. (Eds.), 2004. Dynamic Stochastic Optimization. Vol. 532 of Lecture Notes in Economics and Mathematical Systems. Springer, Berlin.

Messner, S., Golodnikov, A., Gritsevskii, A., 1996. A stochastic version of the dynamic linear programming model message iii. Energy 21 (9), 775-784.

Messner, S., Schrattenholzer, L., March 2000. Message-macro: Linking an energy supply model with a macroeconomic module and solving it iteratively. Energy 25 (3), 267-282.

Messner, S., Strubegger, M., 1995. User's guide for message iii. IIASA working paper WP-95-69, International Institute for Applied Systems Analysis (IIASA), Laxenburg.

Metz, B., Davidson, O., Swart, R., Pan, J. (Eds.), 2001. Climate Change 2001: Mitigation. Third Assessment Report of the IPCC. Cambridge University Press, Cambridge.

URL http://www.grida.no/climate/ipcc\_tar/wg3/

Nakićenović, N., Grübler, A., McDonald, A. (Eds.), 1998. IIASA-WEC Global Energy Perspectives. Cambridge University Press, Cambridge.

URL http://www.iiasa.ac.at/cgi-bin/ecs/book\_dyn/bookcnt.py 
Nakicenovic, N., Riahi, K., 2001. An assessment of technological change across selected energy scenarios. Report, World Energy Council (WEC), London.

Nakićenović, N., Swart, R. (Eds.), October 2000. IPCC Special Report on Emissions Scenarios. IPCC Special Reports. Cambridge University Press, Cambridge. URL http://www.grida.no/climate/ipcc/emission/

Palmquist, J., Rockafellar, R. T., Uryasev, S., 1999. Portfolio optimization with conditional value-at-risk objective and constraints. Tech. rep., Center for Applied Optimization, Dept. of Industrial and Systems Engineering, University of Florida.

Peterson, S., 2006. Uncertainty and economic analysis of climate change: A survey of approaches and findings. Environmental Modeling and Assessment 11 (1), $1-17$.

Pflug, G., Roemisch, W., 2007. Modeling, Measuring and Managing Risk. World Scientific Publishing Company, London.

Pizer, W. A., 1999. The optimal choice of climate change policy in the presence of uncertainty. Resource and Energy Economics 21 (3-4), 255-287.

R Development Core Team, 2008. R: A Language and Environment for Statistical Computing. R Foundation for Statistical Computing, Vienna, Austria, ISBN 3-900051-07-0.

URL http://www.R-project.org

Rao, S., Riahi, K., 2006. The role of non- $\mathrm{CO}_{2}$ greenhouse gases in climate change mitigation: Long-term scenarios for the 21st century. Energy Journal 27 (Special Issue Nov.), 177-200.

Riahi, K., Grübler, A., Nakicenovic, N., 2007. Scenarios of long-term socio-economic and environmental development under climate stabilization. Technological Forecasting and Social Change 74 (7), 887-935.

Riahi, K., Roehrl, R. A., 2000. Greenhouse gas emissions in a dynamics-as-usual scenario of economic and energy development. Technological Forecasting and Social Change 63 (2-3), 175-205.

Rockafellar, R. T., Uryasev, S., 2000. Optimization of conditional value-at-risk. J. Risk 2 (3), 21-41.

Rogner, H. H., 1997. An assessment of world hydrocarbon resources. Annual Review of Energy and the Environment 22 (1), 217-262.

Rokityanskiy, D., Bentez, P. C., Kraxner, F., McCallum, I., Obersteiner, M., Rametsteiner, E., Yamagata, Y., 2007. Geographically explicit global modeling of land-use change, carbon sequestration, and biomass supply. Technological Forecasting and Social Change 74 (7), 1057-1082. 
Stirling, A., March 1994. Diversity and ignorance in electricity supply investment - addressing the solution rather than the problem. Energy Policy 22 (3), $195-216$.

Stirling, A., 1998. On the economics and analysis of diversity. Electronic Working Paper 28, University of Sussex, Brighton.

Wigley, T., October 2003 2003. MAGICC/SCENGEN 4.1: Technical manual. Tech. rep., National Center for Atmospheric Research.

Yan, J., 2007. Enjoy the joy of copulas: with a package copula. Journal of Statistical Software 21 (4), 1-21.

Yohe, G., Andronova, N., Schlesinger, M., 2004. Climate: To hedge or not against an uncertain climate future? Science 306 (5695), 416-417.

Zhang, Y., Pinder, G., 2004. Latin hypercube lattice sample selection strategy for correlated random hydraulic conductivity fields. Water Resources Research 39 (8), 1226.

\section{A Model Input Assumptions}

This appendix provides additional information on numerical assumptions that have been used in the model runs as well as technical details about the model implementation.

\section{A.1 Demands}

As described in Section 4 we distinguish the three demand categories electric, nonelectric (direct use) and transportation fuel demand. Demands are defined in terms of baseline final energy consumption derived from the B2 scenario that was developed with the IIASA GGI Integrated Assessment modeling framework [Grübler et al., 2007; Riahi et al., 2007; IIASA GGI, 2007]. Table 2 presents the numerical demand values for the periods 2000, 2050 and 2100 .

\begin{tabular}{lrrr}
\hline demand [EJ] & 2000 & 2050 & 2100 \\
\hline electric & 45.9 & 178.2 & 335.7 \\
non-electric & 168.9 & 348.3 & 362.1 \\
transport & 74.7 & 190.3 & 246.7 \\
\hline
\end{tabular}

Table 2: Final energy demands in the three demand categories for the periods 2000, 2050 and 2100.

These demands can be lowered by additional investments into sectoral energysaving measures which are modeled on the level of discretized two-step conservation cost curves. More details on the energy saving potentials and costs will be provided in the following section on technology data. 


\section{A.2 Technologies}

Descriptions of individual technologies in the model include economic (e.g. investment costs, fixed and variable operation and maintenance costs) as well as technical parameters (e.g. efficiency, emissions, load factor). In our modeling framework only economic parameters, i.e. either investment or variable operation and maintenance costs, are assumed to be uncertain whereas all other parameters are treated deterministically and in addition do not include any time-dependence to simplify interpretation of results.

\begin{tabular}{|c|c|c|c|c|c|c|c|c|c|}
\hline technology & pll & plf & eff & inv & $\begin{array}{l}\text { fom } \\
2000\end{array}$ & vom & inv & $\begin{array}{l}\text { fom } \\
2100\end{array}$ & vom \\
\hline coal extraction & 10 & 1.00 & 1.00 & 130 & & 35 & 130 & & 35 \\
\hline oil conv. extraction & 10 & 1.00 & 0.96 & 150 & & 80 & 150 & & 80 \\
\hline oil unconv. extraction & 10 & 1.00 & 0.82 & 225 & & 140 & 225 & & 140 \\
\hline gas conv. extraction & 10 & 1.00 & 0.97 & 100 & & 75 & 100 & & 75 \\
\hline gas unconv. extraction & 10 & 1.00 & 0.92 & 180 & & 160 & 180 & & 160 \\
\hline biomass < 3US\$/GJ & 10 & 1.00 & 1.00 & & & 65 & & & 65 \\
\hline biomass $\geq 3 \mathrm{US} \$ / \mathrm{GJ}$ & 10 & 1.00 & 1.00 & & & 125 & & & 125 \\
\hline nuclear füel & 10 & 1.00 & 0.50 & & & 30 & & & 30 \\
\hline coal power plant & 30 & 0.75 & 0.38 & 1300 & 74 & & 1100 & 62.6 & \\
\hline gas combined cycle & 30 & 0.75 & 0.50 & 716 & 51 & & 400 & 32 & \\
\hline nuclear power plant & 30 & 0.75 & 0.38 & 2500 & 108 & & 1800 & 99 & \\
\hline biomass power plant & 30 & 0.75 & 0.33 & 1567 & 82 & & 1200 & 68 & \\
\hline hydro power plant & 50 & 0.42 & 0.38 & 2500 & 40 & & 2500 & 40 & \\
\hline $\begin{array}{l}\text { wind turbine (cat. } 1) \\
\text { wind turbine }\end{array}$ & 30 & $\begin{array}{l}0.34 \\
0.22\end{array}$ & 0.38 & 1344 & 56 & & 600 & 37 & \\
\hline solar PV & 30 & $\begin{array}{l}0.22 \\
0.25\end{array}$ & 0.38 & 4756 & 111 & & 1000 & 48 & \\
\hline backup (e.g. CAS) & 30 & 0.50 & 0.80 & 500 & 20 & & 500 & 20 & \\
\hline coal CCS module & 30 & 0.75 & -.25 & 705 & & 55.9 & 705 & & 55.9 \\
\hline gas CCS module & 30 & 0.75 & -.13 & 503 & & 19.8 & 503 & & 19.8 \\
\hline biomass CCS module & 30 & 0.75 & -.25 & 846 & & 109 & 846 & & 109 \\
\hline hydrogen electrolysis & 30 & 0.95 & 0.80 & 452 & 20 & 4 & 380 & 15 & 4 \\
\hline coal methanol & 30 & 0.90 & 0.63 & 1350 & 76 & 10 & 1150 & 76 & 10 \\
\hline gas methanol & 30 & 0.90 & 0.68 & 630 & 46 & 5.4 & 480 & 35 & 5.4 \\
\hline bioethanol & 30 & 0.90 & 0.87 & 1400 & 74 & 8 & 507 & 55 & 8 \\
\hline refinery & 30 & 0.90 & 0.93 & 66 & 7.5 & & 66 & 7.5 & \\
\hline electricity t/d & 30 & 0.55 & 0.90 & 800 & 55 & 18 & 800 & 55 & 18 \\
\hline $\operatorname{gas} \mathrm{t} / \mathrm{d}$ & 30 & 0.70 & 0.95 & 200 & 24 & 3.5 & 200 & 24 & 3.5 \\
\hline
\end{tabular}

Table 3: Deterministic technology-specific parameters (pll in years, inv and fom in $\mathrm{US} \$ / \mathrm{kW}$ and vom in US\$/kWyr).

Due to the large potential for wind power, we distinguish two categories with different wind conditions which were derived from the analysis by de Vries et al. [2007]. The cost data for the two categories are identical, just the load factor is assumed to be different to reflect the difference in wind conditions. Potentials for the two wind categories as well as for other renewable energy carriers are summarized in Table 5 of the following section. 


\section{A.2.1 Deterministic Parameters}

Table 3 summarizes the assumptions made for all parameters of individual technologies. As mentioned above, the technical parameters in the first three columns of the table $(\mathrm{pll}=$ plant lifetime, plf $=$ plant load factor, eff $=$ net conversion efficiency) are assumed to be time-independent. In contrast to that, economic parameters (inv $=$ investment costs, fom $=$ fixed operation and maintenance costs, vom $=$ variable operation and maintenance costs) typically vary over time. Therefore, Table 3 contains two sets of these parameters, one showing the value in the base year 2000 and one for the year 2100. The interpolation procedure between these two values is described in Section 4.2 and is illustrated in Figure 5 where additional technical details are provided in the following section on stochastic parameters.

As mentioned in Section 4 we do not model individual technologies in the enduse sectors, but have chosen to use discretized conservation cost curves instead. These cost curves were derived from a set of model runs (B2 baseline, 670 ppmv and 480 ppmv stabilization scenarios) with the 11-regional MESSAGE-MACRO model [Messner and Strubegger, 1995; Messner and Schrattenholzer, 2000; Riahi et al., 2007] which are documented in the corresponding scenario database [IIASA GGI, 2007]. Original scenario data were aggregated to the global level, after which an exponential trend in time was fitted to the data to obtain smooth curves. The resulting two-step discretizations of these conservation cost curves are summarized in Table 4, for the first year they become available to the model, i.e. in 2010, as well as for 2050 and for the end of the model's time horizon 2100. This procedure allows us to roughly reproduce the demand response in stabilization scenarios of the much more detailed MESSAGE-MACRO model which is part of IIASA's Integrated Assessment modeling framework [Riahi et al., 2007] without adding the same degree of technological detail.

\begin{tabular}{|c|c|c|c|c|c|c|}
\hline conservation & \multicolumn{3}{|c|}{ potential [EJ] } & \multicolumn{3}{|c|}{$\mathrm{S}[\mathrm{US} \$ / \mathrm{GJ}]$} \\
\hline cate & 2010 & 2050 & 2100 & 2010 & 2050 & 2100 \\
\hline eles & & & 30.84 & 16.62 & 17.82 & 19.47 \\
\hline & & & & 19. & 20. & .97 \\
\hline & & & & & & 10.18 \\
\hline & 9.0 & & & & & 18.20 \\
\hline & 0.82 & & & 4.0 & & 12.49 \\
\hline transport 2 & 4.23 & 13.50 & 57.68 & 4.28 & & 18.74 \\
\hline
\end{tabular}

Table 4: Conservation cost curve parameters for the three demand categories.

The resource base of fossil energy carriers has its foundations in [Rogner, 1997] and is adjusted to the B2 storyline [Riahi et al., 2007; IIASA GGI, 2007]. For coal all grades A-E are included, conventional oil includes categories I-III and unconventional oil categories IV-V. Conventional gas is an aggregate of categories I-III and unconventional gas covers categories IV-VI. Potentials of renewable energy carriers with the exception of wind are based on the estimates used in [Riahi et al., 2007; IIASA GGI, 2007]. Because of the large potential for wind we distinguish two categories with different wind conditions which are based on the B2 potentials published by de Vries et al. [2007]. The assumptions used in the model are documented in Table 5. The values provided for fossil energy carriers correspond to the resource 
base available in the base year 2000. The quantities available in later years are then a result of the optimization procedure. For renewable energies the potentials are provided on an annual basis.

\begin{tabular}{lrrr}
\hline resource category & 2000 & 2050 & 2100 \\
\hline coal & 260450 & endogenous \\
oil conventional & 11770 & endogenous \\
oil unconventional & 8890 & endogenous \\
gas conventional & 17920 & endogenous \\
gas unconventional & 23020 & \multicolumn{2}{c}{ endogenous } \\
biomass < 3US\$/GJ & 107 & 132 & 149 \\
biomass $\geq 3$ US\$/GJ & 22 & 62 & 106 \\
hydro & 13 & 35 & 50 \\
wind (cat. 1) & 20 & 54 & 54 \\
wind (cat. 2) & 23 & 61 & 61 \\
solar PV & 2.3 & 33 & 73 \\
\hline
\end{tabular}

Table 5: Fossil fuel resource base in 2000 and renewable energy potentials in 2000, 2050 and 2100 [EJ]

To calculate $\mathrm{CO}_{2}$ emissions that originate from burning fossil energy carriers we uniformly apply the following emission factors on the basis of the lower heating value.

- coal: $25.8 \mathrm{MtC} / \mathrm{EJ}$

- oil: 20.0 MtC/EJ

- natural gas: $15.3 \mathrm{MtC} / \mathrm{EJ}$

Biomass is predominantly provided by the forest sector and therefore assumed to be carbon neutral as a result of a sustainable production approach (see [Rokityanskiy et al., 2007] for details).

\section{A.2.2 Stochastic Parameters}

The PDFs of uncertain technology investment costs have been determined in the following way: Based on a review of technological change across selected energy scenarios [Nakicenovic and Riahi, 2001] we have determined the expected value of costs in the year 2100 by calculating the median across the scenario assumptions. Also the variability of costs has been estimated from this source as described in Section 4.2. However, we only take the numerical values as a first indicator and assign the next highest uncertainty category (standard deviation $\sigma$ : low uncertainty $\sigma_{\text {low }}=0.15$, medium uncertainty $\sigma_{\text {med }}=0.3$ and high uncertainty $\sigma_{\text {high }}=0.6$ ) to the technologies, because of the limited set of scenarios that was included in the analysis. This procedure was applied to most electricity generation technologies, except the backup technology, and all liquid fuel technologies with the exception of the oil refinery. All other technologies were assigned to one of the three uncertainty categories based on experts' opinion, the result of which is shown in Figure 4 as mentioned in Section 4.2. 
Figures 12 and 13 show histograms and pair-wise scatter-plots for the nine electricity generation technologies based on the samples that result from the above described procedure. In Figure 13 only scatter-plots for pairs of technologies with a correlation coefficient larger than 0.05 are shown. The investment costs correspond to the period 2100 where random sampling was used to generate samples of size $N=20000$.
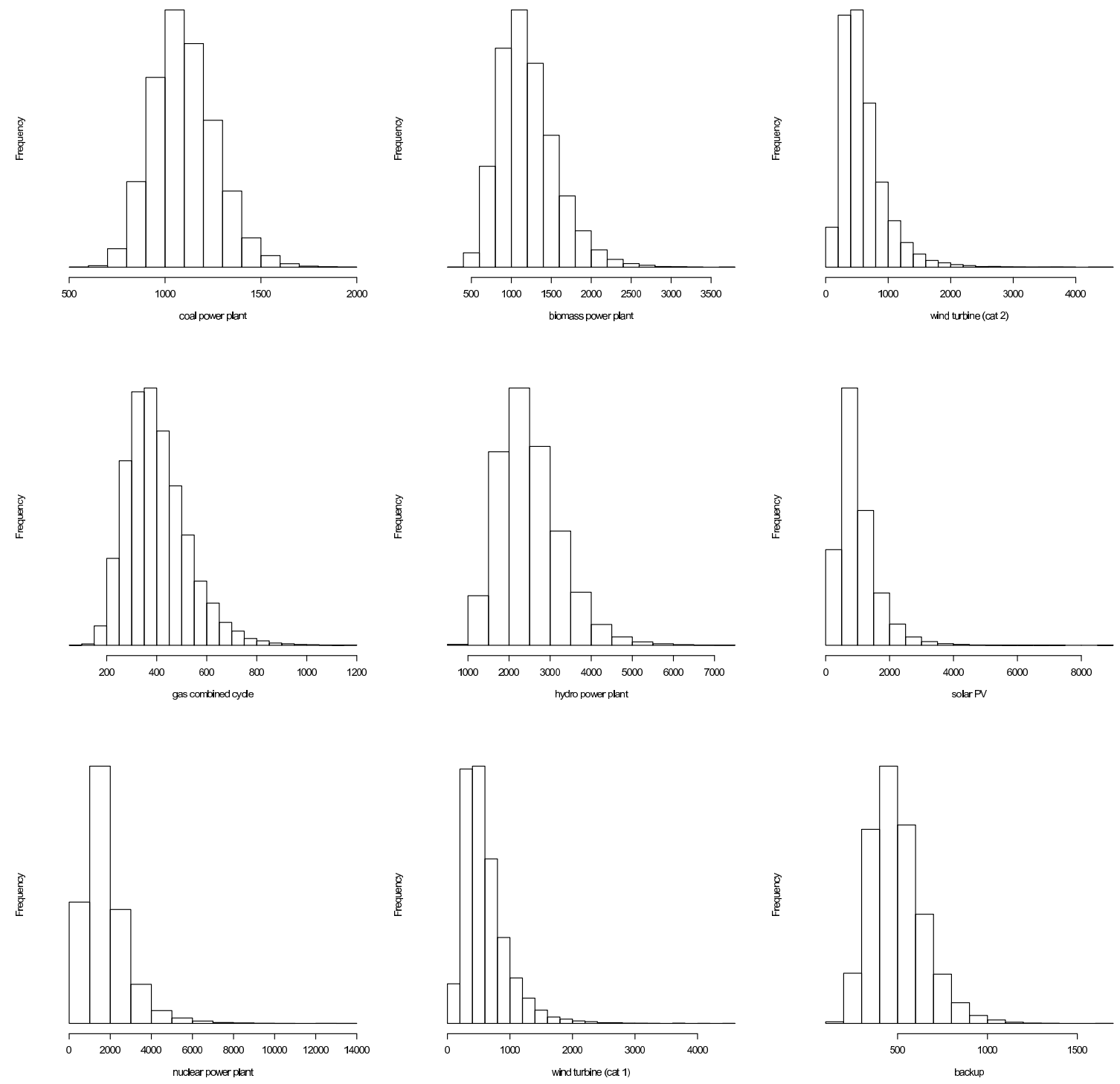

Figure 12: Histograms of investment costs [US $\$ / \mathrm{kW}$ ] of electricity generation technologies in the period 2100 for a sample size of $N=20000$ (random sampling).

To derive random cost paths for the model's full time horizon (2000 - 2100) we proceed in the following way: Based on one of the two sampling procedures described in Section 2.3 we generate $N$ sets of random cost parameters for the period 2100 . We then exponentially interpolate between the base year value in 2000 and the random parameter values in 2100. To fix the third parameter in the exponential function $y(x)=y_{0}+A \cdot \exp (-\lambda x)$ we assume the asymptote $y_{0}$ to be $1 \%$ higher (lower) than the 2100 value depending on whether the 2100 is higher (lower) than the 2000 value. 

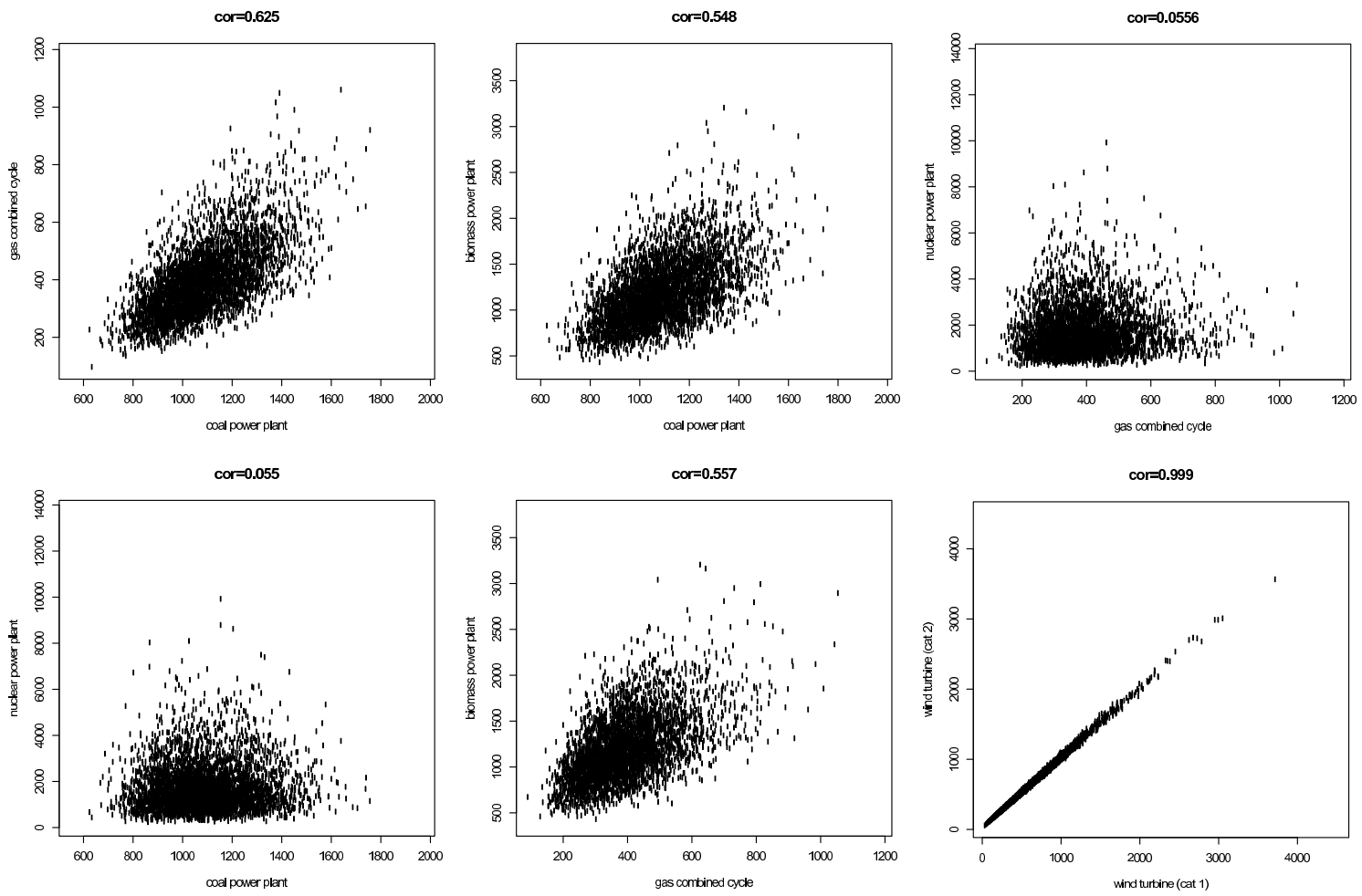

Figure 13: Pair-wise scatter-plots of investment costs [US $\$ / \mathrm{kW}$ ] of electricity generation technologies in the period 2100 with non-zero correlation $\left(\rho_{i j}>0.05\right)$ for a sample size of $N=20000$ (random sampling).

A graphical illustration of this procedure for the investment costs of a natural gas combined cycle power plant is given in Figure 5 of Section 4.2. In contrast to linear interpolation this procedure approaches the final level of costs relatively quickly typically within the first half of the century - whereas cost levels stay relatively constant in the second half of the century. Therefore, envelopes of costs "widen" quickly, thus creating some overlap of input cost distributions early in the century.

\section{A.3 Carbon Price}

As briefly described in Section 4.2 the carbon price and its distribution in 2100 was derived from a sample of stabilization scenarios from the IPCC scenario database [Hanaoka et al., 2006]. A lognormal distribution fits the entire set of carbon prices from a total of 134 stabilization scenarios quite well (see Figure 14). In addition, a Shapiro-Wilk normality test was conducted with the logarithmized data set which provides a $p$-value of 0.14 and therefore does not allow to reject the hypothesis of the logarithmized data being normally distributed.

The actual fit of the lognormal distribution used in the one-regional global energy systems model was obtained from a subsample of stabilization scenarios with $\mathrm{CO}_{2}$-equivalent concentration targets of $650 \mathrm{ppmv}$ and above. Parameters were determined by taking mean and standard deviation of the logarithmized dataset. This procedure resulted in numerical values for the expected value of $\bar{p}_{c}=372 \mathrm{US} \$ / \mathrm{tC}$ and of $\sigma_{c}=520 \mathrm{US} \$ / \mathrm{tC}$ for the standard deviation. The resulting values (mean as well as 


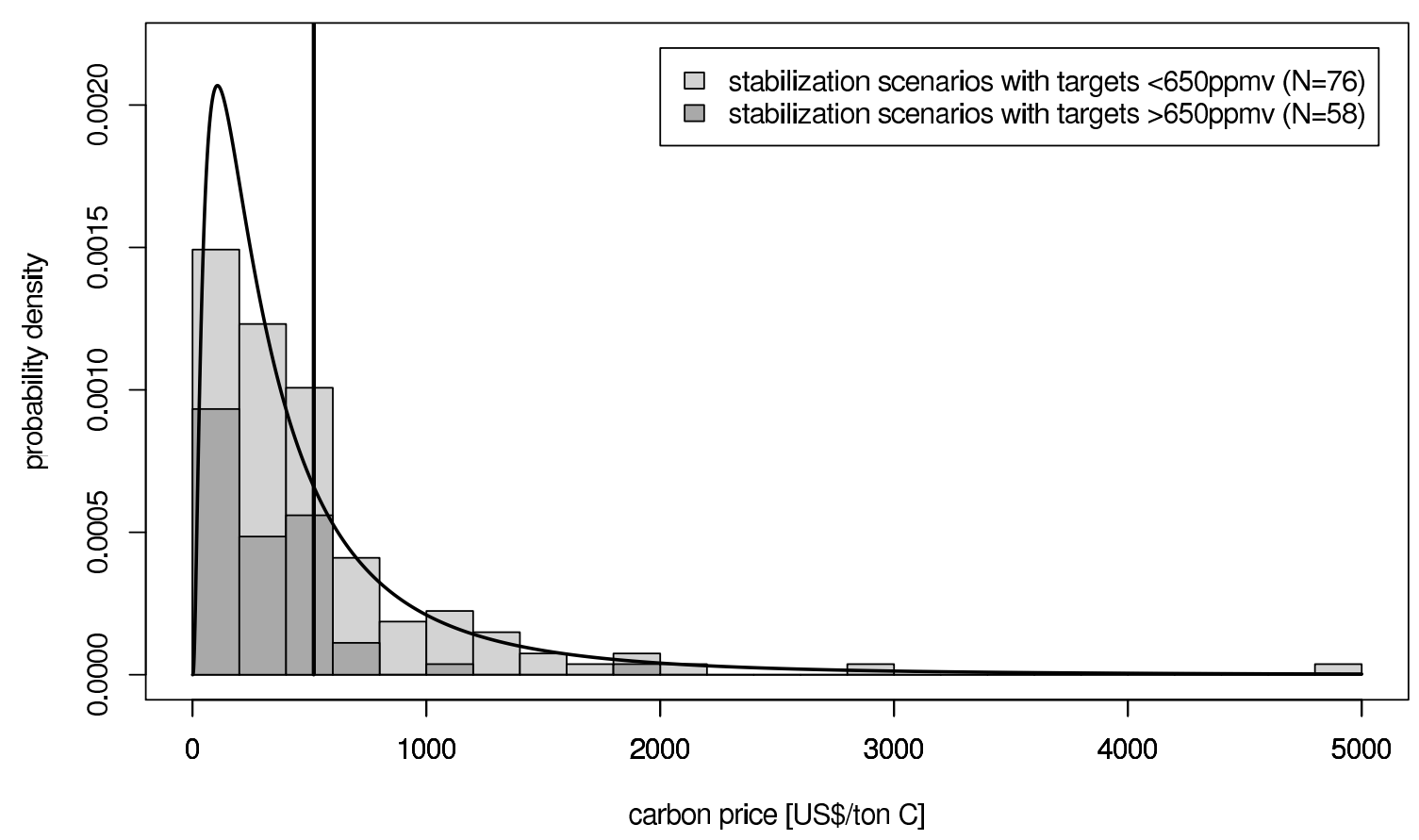

Figure 14: Carbon price distribution of 134 stabilization scenarios in the IPCC scenario database [Hanaoka et al., 2006] and lognormal fit to data.

stochastic realizations) for the year 2100 were subsequently propagated backwards to 2010 with the model's $5 \%$ discount rate to obtain carbon price trajectories.

\section{B Sample Function Approximation}

As described in Section 2.3, the risk measures $R(\mathbf{x}, \omega)$ are in practical model applications estimated by $N$ independent realizations, so-called sample functions, where $N \rightarrow \infty$.

$$
R(\mathbf{x}) \rightarrow R^{N}(\mathbf{x})=\frac{1}{N} \sum_{s=1}^{N} R\left(\mathbf{x}, \omega^{s}\right)
$$

The sample size $N$ is evaluated by experiment, i.e. $N$ is increased as long as different draws of the same sample size still produce noticeably varying solutions. Although it is problematic to proof convergence from a theoretical point of view, we find that in practice such approximations work better than expected theoretically (see also Ermoliev and Wets [1988, Chap. 1.8]). For this purpose we introduce a so-called Taxicab- or 1-norm as a quantitative measure

$$
\|\mathbf{x}\|_{1}=\sum_{i}\left|x_{i}\right|
$$

where $\mathbf{x}=\left(\mathbf{x}_{1}, \ldots, \mathbf{x}_{T}\right)$ is the vector of the model's decision variables for all periods $t=1 \ldots T$.

Based on the Taxicab-norm we define a convergence criterion to measure (rela- 
tive) deviations between two solutions $i$ and $j$ with identical sample size $N$

$$
\Delta_{i j}=\frac{\left\|\mathbf{x}_{i}-\mathbf{x}_{j}\right\|_{1}}{\left\|\mathbf{x}_{i}+\mathbf{x}_{j}\right\|_{1}}
$$

where $\mathbf{x}_{i}$ and $\mathbf{x}_{j}$ are the solution vectors of the two solutions respectively. We require the maximum of all pair-wise distances $\Delta_{i j}$ to be less than a $\varepsilon>0$

$$
\max _{i, j} \Delta_{i j} \leq \varepsilon
$$

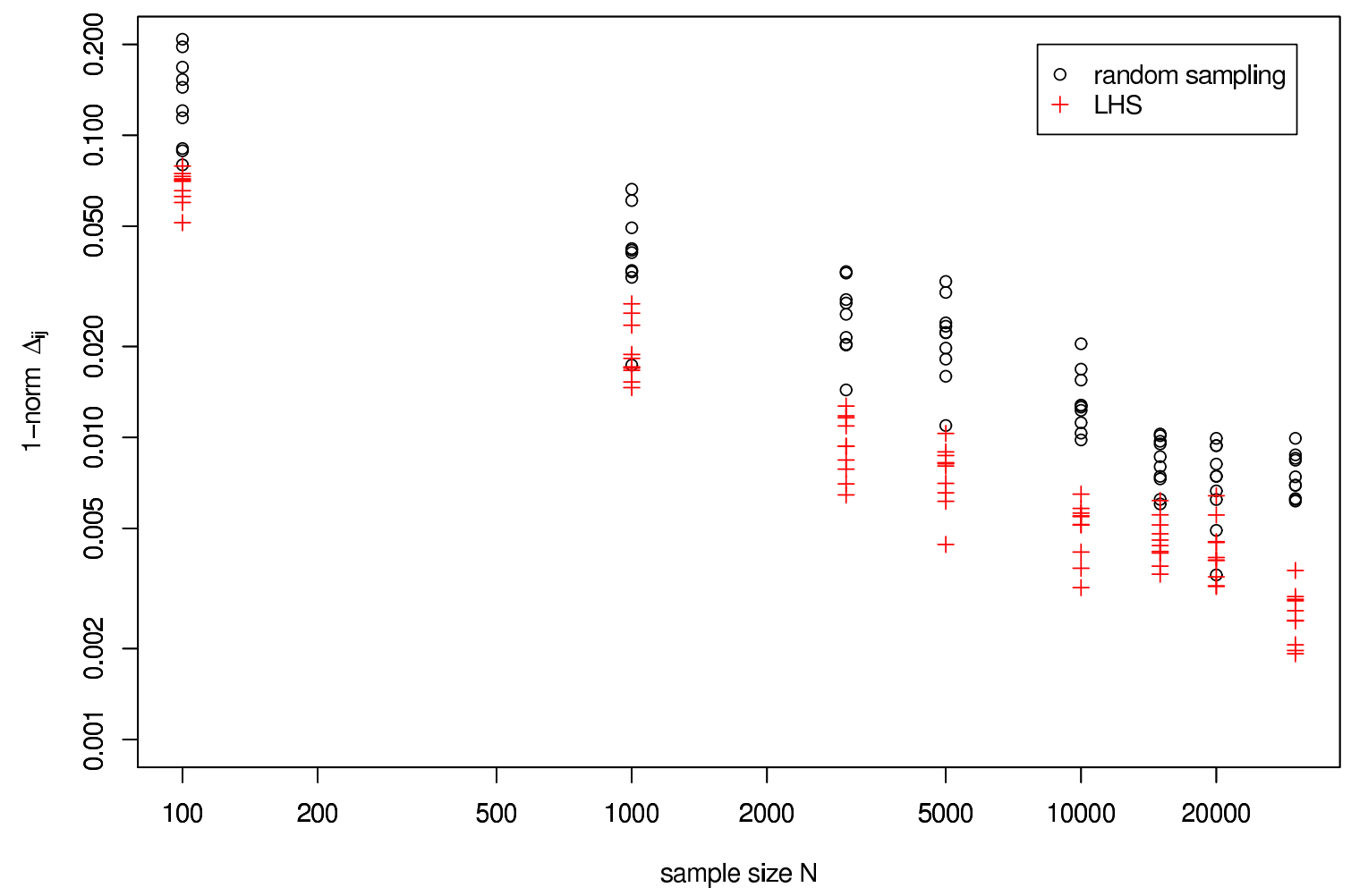

Figure 15: Pairwise convergence measure $\Delta_{i j}$ as a function of sample size $N$ for random sampling and LHS (5 model runs resulting in 10 combinations) - doublelogarithmic scale

In realistic applications of energy systems models, the sample size $N$ imposes restrictions on the number of uncertain parameters. Therefore, improved sampling methods to decrease the sample size $N$, but at the same time satisfying a given convergence criterion $\varepsilon$, are a possibility to reduce computational effort or alternatively increase the number of uncertain parameters. For this purpose we employ latin hypercube sampling (LHS) (e.g. [Iman and Conover, 1980]) in contrast to random sampling. Correlations among latin hypercube sampled parameters are introduced with the algorithm suggested by Iman and Conover [1982] (see also [Zhang and Pinder, 2004]).

The convergence behavior of LHS in comparison with random sampling can be seen in Figure 15. This figure was generated with the model presented in Section 4 on the basis of 5 model runs for each sample size $N$ with random and latin hypercube 
sampling. LHS gives significantly better convergence across all sample sizes $N$ that have been analyzed. To obtain the same convergence level $\varepsilon$ with LHS the sample size can be chosen almost one order of magnitude smaller than with random sampling. Therefore, the additional effort for employing LHS is well justified, in particular for larger models where memory limitations can become a constraint. As a result of these numerical experiments we used LHS for all model runs presented in this article. The sample size was chosen to be $N=20000$ corresponding to a convergence criterion of $\varepsilon=0.75 \%$. 